\title{
Stereoisomers of Saponins in Panax notoginseng (Sanqi): A Review
}

\author{
Ming Peng ${ }^{1,2 t}$, Ya X. Yi1t, Tong Zhang ${ }^{1 *}$, Yue Ding ${ }^{3 \star}$ and Jian Le ${ }^{2,4}$ \\ 'School of Pharmacy, Shanghai University of Traditional Chinese Medicine, Shanghai, China, ${ }^{2}$ Department of Chemistry, \\ Shanghai Institute for Food and Drug Control, Shanghai, China, ${ }^{3}$ Experiment Center for Teaching and Learning, Shanghai \\ University of Traditional Chinese Medicine, Shanghai, China, ${ }^{4}$ Shanghai Institute of Pharmaceutical Industry, China State \\ Institute of Pharmaceutical Industry, Shanghai, China
}

OPEN ACCESS

Edited by:

Matthias F. Melzig,

Freie Universität Berlin, Germany

Reviewed by:

Pinarosa Avato,

Università degli Studi di Bari Aldo

Moro, Italy

Min Ye,

Peking University, China

${ }^{*}$ Correspondence:

Tong Zhang

zhangtdmj@hotmail.com;

zhangtongshutcm@hotmail.com

Yue Ding

dingyue-2001@hotmail.com

tThese authors have contributed equally to this work.

Specialty section:

This article was submitted to

Ethnopharmacology,

a section of the journal

Frontiers in Pharmacology

Received: 08 November 2017

Accepted: 19 February 2018

Published: 13 March 2018

Citation:

Peng $M$, Yi YX, Zhang T, Ding $Y$ and Le J (2018) Stereoisomers of Saponins in Panax notoginseng (Sanqi): A Review.

Front. Pharmacol. 9:188. doi: 10.3389/fphar.2018.00188
Panax notoginseng (Sanqi), a traditional Chinese medical drug which has been applied to medical use for over four centuries, contains high content of dammaranetype tetracyclic triterpenoid saponins. A number of stereoisomeric dammaranetype saponins exist in this precious herb, and some are particularly regarded as "biomarkers" in processed notoginseng. Contemporary researches have indicated that some saponin stereoisomers may show stereospecific pharmacological activities, such as anti-tumor, antioxidative, anti-photoaging, anti-inflammatory, antidiabetic, and neuro-protective activities, as well as stereoselective effects on ion channel current regulation, cardiovascular system, and immune system. The current review provides a comprehensive overview of chemical compositions of raw and processed $P$. notoginseng with a particular emphasis on saponin stereoisomers. Besides, the pharmacological and pharmacokinetic researches, as well as determination and biotechnological preparation methods of stereoisomeric saponins in notoginseng are discussed extensively.

Keywords: Panax notoginseng, processing, ginsenosides, saponins, stereoisomer, stereospecific, chiral

\section{INTRODUCTION}

Notoginseng, the root of Panax notoginseng (Burk.) F. H. Chen (P. notoginseng), also called Sanqi or Sanchi, is a precious traditional Chinese medical drug which has a history of medical use for over 400 years. The main active components of notoginseng include saponins, dencichine, flavonoids, polysaccharides and fatty acids, etc. (Wang et al., 2006, 2016). Although some non-saponin constitutents exhibit hemostasis, neuroprotective and immunity activities (Huang et al., 2014; Jia et al., 2014), a majority of the pharmacological functions of notoginseng are basically attributed to its saponin components (Shi et al., 2016). Contemporary research have discovered that Panax notoginseng saponins (PNS) can be effective in the treatment of cardiovascular diseases (Yang X. et al., 2014), such as atherosclerosis (Liu G. et al., 2009), hypertension (Pan et al., 2012), myocardial ischemia (Han et al., 2013), and aortic intimal hyperplasia (Wu et al., 2010), etc. Moreover, PNS also possesses the biological activities of anti-cancer (Yang et al., 2016), anti-hyperlipoidemia (Xia et al., 2011), anti-hyperglycemia (Yang et al., 2010), anti-inflammatory response (Rhule et al., 2008), antidepression (Xiang et al., 2011), neuroprotective effect (Luo et al., 2010), antioxidative effect (Zhou et al., 2014), and bone formation stimulation activity (Chen et al., 2012), etc.

Unlike its close relatives, i.e., Panax ginseng and Panax quinque foilium, P. notoginseng possesses dammarane-type tetracyclic triterpenoid saponins exclusively (Wang et al., 2006), and the total amount of dammarane-type saponins in $P$. notoginseng is evidently greater than that in the 
other two species (Wan et al., 2007). Dammarane-type saponins can essentially be divided into two groups: protopanaxadiol (PPD) and protopanaxatriol (PPT) type. Both of PPD and PPT aglycons bear chiral carbons in their structure skeletons, which lead to the stereoisomerism of PPD and PPT saponins (Figures 1A-D). Interestingly, although stereoisomeric compounds are widely distributed in herbal medical drugs, the chemical and pharmacological difference in stereoisomers in phytochemistry has not been extensively studied until recently, and the research targets include triterpenoid saponins (Nose et al., 1994), flavanones (Ren et al., 2007), Schisandrin B (Luk et al., 2008), alkaloids (Krizevski et al., 2010), fatty acids (Nagai et al., 2010), and pyranocoumarins (Song et al., 2014b).

The investigation on C-20 stereoisomerism of dammaranetype saponins has aroused the interest of researchers in recent years. Generally speaking, stereoisomerism in phytochemistry refers to optical and geometric isomerism, respectively. Not surprisingly, raw notoginseng is discovered to contain 20(S)-optical isomer of saponins basically, such as 20(S)-notoginsengoside $R_{2}, 20(\mathrm{~S})$-ginsenoside $\mathrm{Rg}_{2}$ and 20(S)-ginsenoside $\mathrm{Rh}_{1}$. However, it has been demonstrated that the processing procedures of $P$. notoginseng, e.g., steaming, heating, frying, etc., may lead to the cleavage of glycosyl linkage bonds and the dehydration at C-20. During the processes, some originally existed saponins in raw notoginseng would gradually be deglycosylated at C-20 to optical saponin epimers, such as 20(S)-/20(R)-ginsenoside $\mathrm{Rg}_{3}$ and 20(S)-/20(R)-ginsenoside $\mathrm{Rh}_{2}$, as well as be dehydrated at C-20 to geometric isomers, i.e., cis-trans isomers, such as ginsenoside $\mathrm{RK}_{3}$ and $\mathrm{Rh}_{4}, \mathrm{RK}_{1}$ and $\mathrm{Rg}_{5}, \mathrm{RK}_{2}$ and $\mathrm{Rh}_{3}$, etc. (Figures $\mathbf{1 E}-\mathbf{H}$ ) (Wang et al., 2012). Based on previously published studies, some secondary saponins are of high biological activities compared with the original ones in raw $P$. notoginseng. So far, literatures have indicated that saponin stereoisomers may exhibit significant difference in the following aspects: (1) physical and chemical properties; (2) methods of isolation, analysis and preparation; (3) biological, pharmacological, pharmacodynamic, and clinical evaluations; (4) key parameters of pharmacokinetics. However, the biotechnological difference of the stereoisomers of saponins in notoginseng has not been extensively reviewed so far. This article compiles a review of chemical compositions of raw and processed notoginseng with a particular emphasis on the stereoisomeric saponins. Besides, the determination, preparation methods, and the pharmacological and pharmacokinetic researches of those saponin stereoisomers are also elaborated.

\section{CHEMISTRY}

\section{Dammarane-Type Saponins in Raw $P$. notoginseng}

So far extensive researches have been performed on the identification and analysis of saponins in raw P. notoginseng. The nomenclatures of the saponins isolated from $P$. notoginseng are generally ginsenoside and notoginsenoside. One distinguishing feature of notoginseng is that all of the saponins can be classified into PPD, PPT or their derivative types. However, the saponins profiles in different medicinal parts, e.g., root, rhizome, stem, flower, and leaf, etc., of notoginseng are of huge difference (Wan et al., 2012). The flower buds of notoginseng contain PPD type saponins predominantly. Nevertheless, both PPD and PPT type saponins are plentiful in roots (Yang et al., 2013). HPLC-ELSD and LC-QTOF-MS analysis also revealed the fact that the majority saponins in notoginseng leaves are of PPD types (Wang et al., 2015). An UPLC-ESIMS method combined with principal component analysis (PCA) tentatively gave critical marker compounds in different part of notoginseng for the first time. The marker compounds assigned are listed below: (1) in roots: ginsenoside $\mathrm{Rb}_{1}$ and $\mathrm{Rg}_{1}$, notoginsenoside $\mathrm{A}$ and $\mathrm{B}$, and 20-O-glucoginsenoside-Rf; (2) in flower buds: notoginsenoside $\mathrm{Q}, \mathrm{S}$ and $\mathrm{Fc}$, ginsenoside $\mathrm{Rb}_{2}, \mathrm{Rb}_{3}$, and $\mathrm{F}_{2}$; (3) in rhizomes: ginsenoside $\mathrm{Re}, \mathrm{Rf}, \mathrm{Rg}_{2}$, $\mathrm{Rc}, \mathrm{Rd}, \mathrm{Rh}_{2}$ notoginsenoside $\mathrm{R}_{1}, \mathrm{R}_{4}, \mathrm{Fa}$ and $\mathrm{H}$, and malonylginsenoside- $\mathrm{Rb}_{1}$ (Dan et al., 2008). It is noteworthy that although most of the naturally existed optical saponins are 20(S)-epimers such as $20(\mathrm{~S})-\mathrm{Rg}_{2}$ and $20(\mathrm{~S})-\mathrm{Rh}_{1}$, there are still investigations indicating $20(\mathrm{R})-\mathrm{Rg}_{3}$ occurred in raw notoginseng (Dan et al., 2008; Qi et al., 2012; Sakah et al., 2013). 20(S)- and 20(R)$\mathrm{Rg}_{3}$ are the only pair of C-20 stereoisomers reported in raw $P$. notoginseng. However, based on our results (Peng et al., 2016b), only 20(S)-form stereoisomeric saponins could be found in raw $P$. notoginseng. Take 20-80 head raw herbs obtained from Yunnan province as an example, 20(S)-notoginsenoside $\mathrm{R}_{1}, 20(\mathrm{~S})-\mathrm{Rg}_{2}$ and $20(\mathrm{~S})-\mathrm{Rh}_{1}$ were found, and the amount was in the range of $1.0-1.9,0.5-1.5$, and $0.3-2.1 \mathrm{mg} / \mathrm{g}$, respectively. The structures and locations of saponins existed in raw and processed $P$. notoginseng are summarized in Figure $\mathbf{1}$ and Tables 1A,B.

\section{The Processing of $P$. notoginseng}

The processing of traditional Chinese medical drug is a national heritage of a Chinese medicinal culture. The purpose of processing can be classified into four points: (1) eliminating or alleviating the toxicity and side effects; (2) changing the medicinal properties; (3) being convenient for formulation and storage; (4) cleaning the medical drug. In the case of $P$. notoginseng, the medicinal properties are altered upon the processing, i.e., baking, steaming, boiling and frying according to literatures and conventional Chinese methods (Lau et al., 2003, 2004; Chan et al., 2007; Sun et al., 2010; Toh et al., 2010; Wang et al., 2012). Among those processing procedures, steaming is most frequently used and the procedure of steaming at $100^{\circ} \mathrm{C}$ for $3 \mathrm{~h}$ has been set as the provincial standard for processed notoginseng powder in Yunnan, China, since April 1, 2013. Temperatures of $100^{\circ} \mathrm{C}$ and $120^{\circ} \mathrm{C}$ are practically used in the processing according to published literatures.

\section{Saponins Produced in Processed $P$. notoginseng}

With the processing of notoginseng, some originally existed saponins will be degraded, accompanied by the generation of secondary saponins, including quite a number of saponin stereoisomers. 


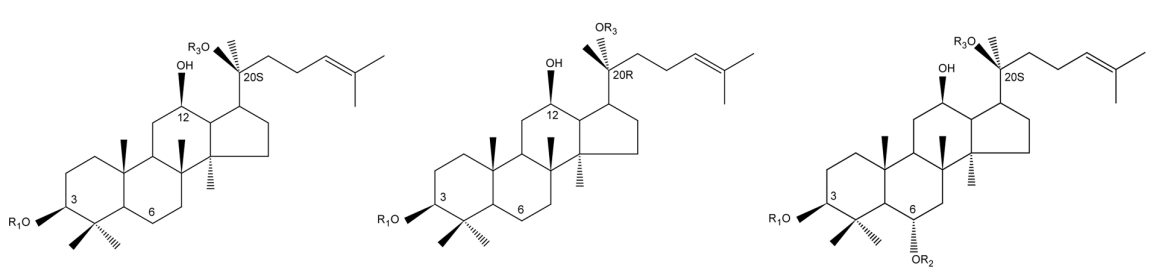

A 20(S)-PPD type

B 20(R)-PPD type

C 20(S)-PPT type

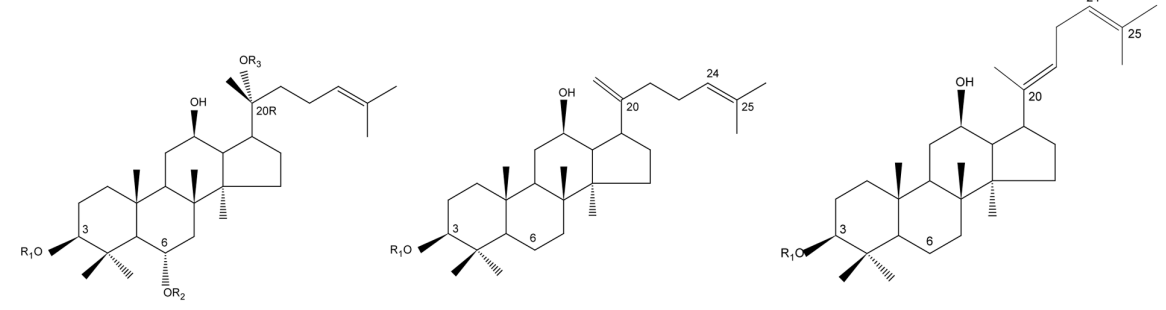

D 20(R)-PPT type E cis C-20 dehydrated PPD type F trans C-20 dehydrated PPD type

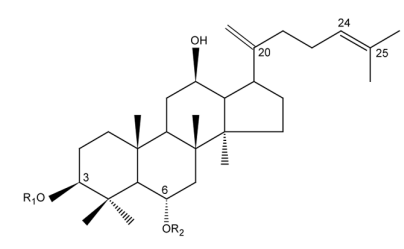

G cis C-20 dehydrated PPT type

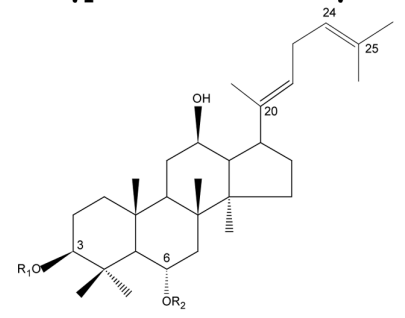

H trans C-20 dehydrated PPT type

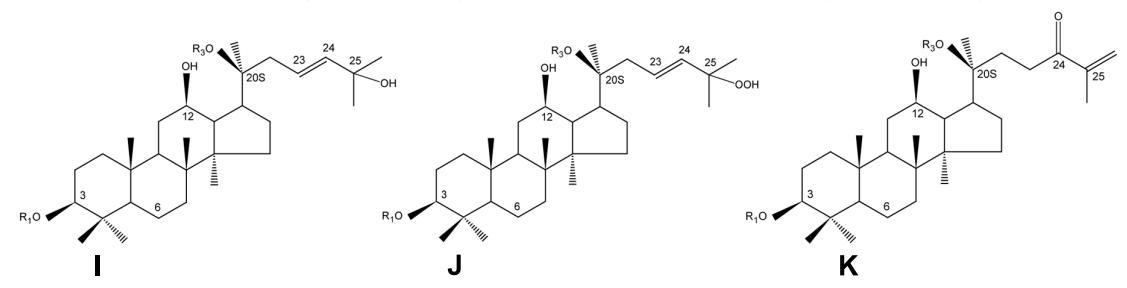

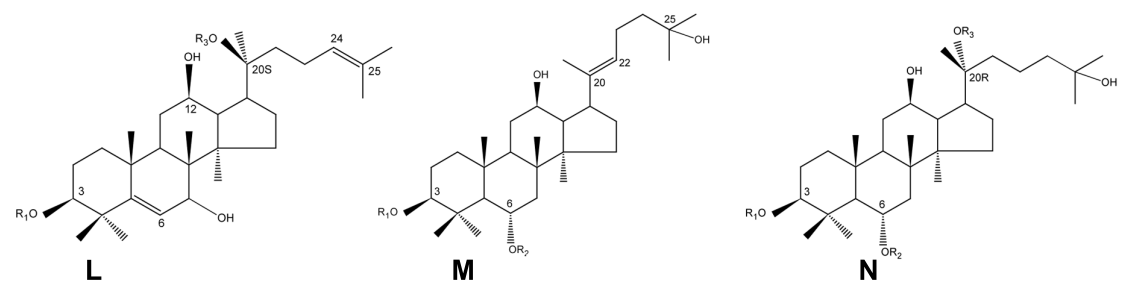

FIGURE 1 | Structure skeletons of saponins existed in raw and processed $P$. notoginseng. The different substituents represented by R1, R2, and R3 in structures of (A-N) have been elaborated in Table 1.

A series of measurements of HPLC-DAD, LC-MS/MS, LC-QTOFMS and NMR, etc., have been performed on the identification of saponins. Although some of the newly generated saponins are regarded as biomarkers for processed notoginseng, not much emphasis has been put on the presence of stereoismeric saponins so far, which is absolutely a very attractive topic.

The research group of Lau et al. (2003) and Lau et al. (2004) is by far the first team to investigate the difference of whole chromatograms of raw and steamed $P$. notoginseng.
Results showed that with the extending of steaming time from 0 to $9 \mathrm{~h}$ in an autoclave at $120^{\circ} \mathrm{C}$, the chromatograms of steamed notoginseng exhibited greater difference with that of raw materials. Except ginsenoside Rc, all the rest of known saponins, i.e., notoginsenoside $\mathrm{R}_{1}$, ginsenoside $\mathrm{Rg}_{1}, \mathrm{Re}, \mathrm{Rb}_{1}$ and Rd were dramatically degraded. The newly occurred saponins include ginsenoside $20(\mathrm{R})-\mathrm{Rh}_{1}, \mathrm{Rk}_{3}, \mathrm{Rh}_{4}, 20(\mathrm{~S})-/ 20(\mathrm{R})-\mathrm{Rg}_{3}$, $\mathrm{Rk}_{1}$ and $\mathrm{Rg}_{5}$, which are all stereoisomeric saponins without exception. 
TABLE 1A | Saponins existed in raw Panax notoginseng.

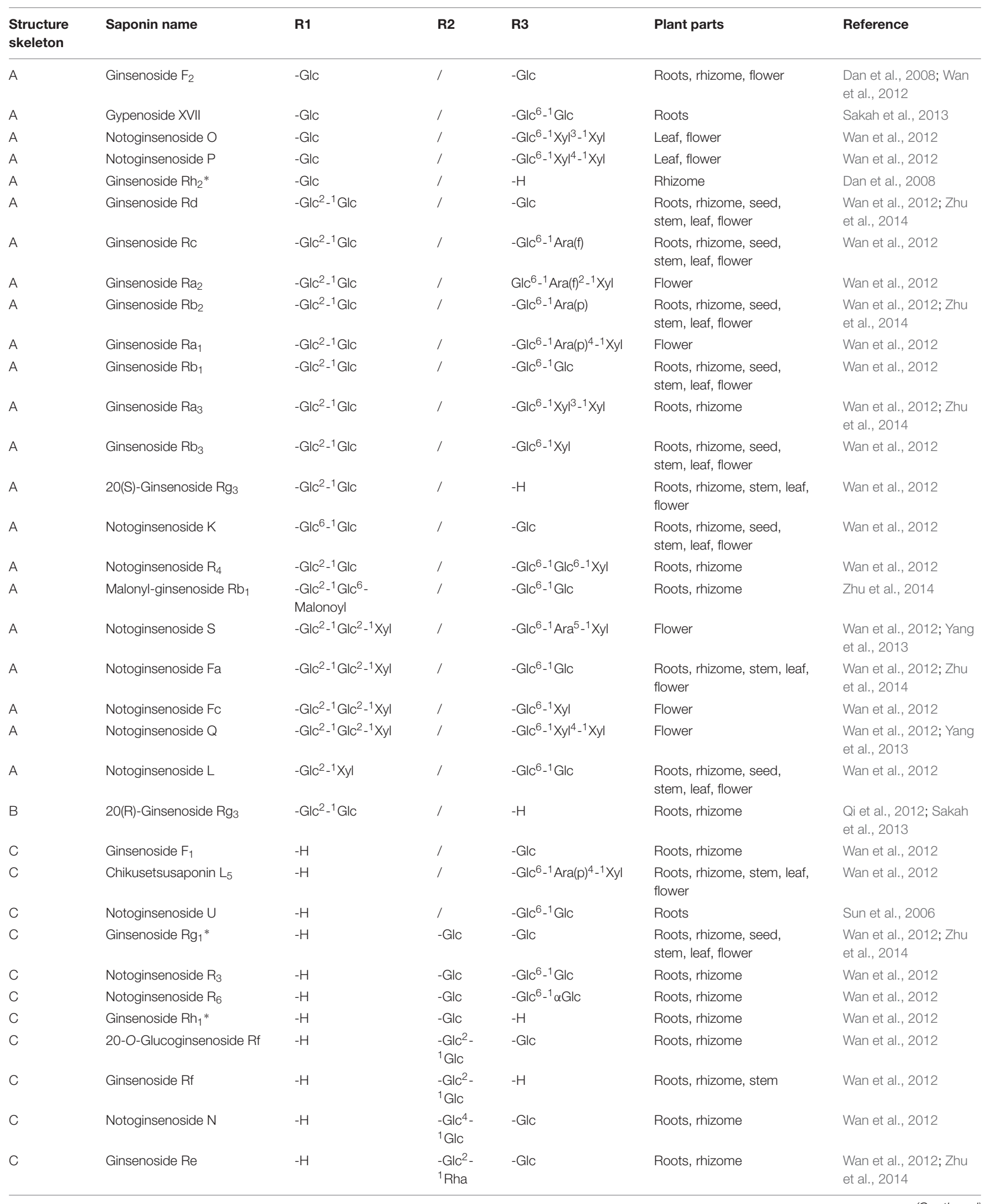


TABLE 1A | Continued

\begin{tabular}{|c|c|c|c|c|c|c|}
\hline $\begin{array}{l}\text { Structure } \\
\text { skeleton }\end{array}$ & Saponin name & R1 & $\mathbf{R} 2$ & R3 & Plant parts & Reference \\
\hline C & Ginsenoside $\mathrm{Rg}_{2}{ }^{*}$ & $-H$ & $\begin{array}{l}-\mathrm{Glc}^{2}- \\
{ }^{1} \text { Rha }\end{array}$ & $-H$ & Roots, rhizome, seed, stem & $\begin{array}{l}\text { Wan et al., 2012; Yang } \\
\text { et al., 2013; Zhu et al., } \\
2014\end{array}$ \\
\hline C & Notoginsenoside $\mathrm{R}_{1}$ & $-H$ & $\begin{array}{l}-\mathrm{Glc}^{2}- \\
{ }^{1} \mathrm{Xyl}\end{array}$ & -Glc & $\begin{array}{l}\text { Roots, rhizome, seed, } \\
\text { stem, leaf, flower }\end{array}$ & $\begin{array}{l}\text { Wan et al., 2012; Zhu } \\
\text { et al., } 2014\end{array}$ \\
\hline । & Notoginsenoside E & $-\mathrm{Glc}^{2}-{ }^{1} \mathrm{Glc}$ & / & -Glc & Roots, rhizome & Wan et al., 2012 \\
\hline । & Notoginsenoside A & $-\mathrm{Glc}^{2}-{ }^{1} \mathrm{Glc}$ & / & $-\mathrm{Glc}^{6}-{ }^{1} \mathrm{Glc}$ & Roots, rhizome & Wan et al., 2012 \\
\hline । & Yesanchinoside H & $-\mathrm{Glc}^{2}-{ }^{1} \mathrm{Glc}$ & / & $-G c^{6}-{ }^{1} X y l$ & Roots, rhizome & Wan et al., 2012 \\
\hline J & Notoginsenoside I & $-\mathrm{Glc}^{2}-{ }^{1} \mathrm{Glc}$ & / & $-\mathrm{Glc}^{6}-{ }^{1} \mathrm{Glc}$ & Roots, rhizome & Wan et al., 2012 \\
\hline K & Notoginsenoside B & $-\mathrm{Glc}^{2}-{ }^{1} \mathrm{Glc}$ & / & $-\mathrm{Glc}^{6}-{ }^{1} \mathrm{Glc}$ & Roots & Dan et al., 2008 \\
\hline
\end{tabular}

* Optical conformation not defined.

TABLE 1B | Saponins produced in processed Panax notoginseng.

\begin{tabular}{|c|c|c|c|c|c|}
\hline $\begin{array}{l}\text { Structure } \\
\text { skeleton }\end{array}$ & Saponin name & R1 & $\mathbf{R 2}$ & R3 & Reference \\
\hline A & 20(S)-Ginsenoside $\mathrm{Rh}_{2}$ & -Glc & / & $-H$ & Chan et al., 2007 \\
\hline A & 20(S)-Ginsenoside $\mathrm{Rs}_{3}$ & $-G c^{2}-1 G^{6} c^{6}-A c$ & / & $-H$ & Chan et al., 2007 \\
\hline A & 6"-O-Acetylginsenoside $\mathrm{Rg}_{3}$ & $-G c^{2}-1 G^{6} c^{6}-A c$ & / & -Glc & Liao et al., 2008 \\
\hline C & 20(S)-Ginsenoside $\mathrm{Rh}_{1}$ & $-H$ & -Glc & $-H$ & Wang et al., 2012 \\
\hline C & Koryoginsenoside- $\mathrm{R}_{1}$ & $-H$ & -Glc $c^{6}-(E)-2-$ Butenoyl & - Glc & Liao et al., 2008 \\
\hline C & Yesanchinoside D & $-H$ & $-G c^{6}-A c$ & -Glc & Liao et al., 2008 \\
\hline C & 20(S)-Ginsenoside $\mathrm{Rg}_{2}$ & $-H$ & $-\mathrm{Glc}^{2}-{ }^{1} \mathrm{Rha}$ & $-H$ & Chan et al., 2007 \\
\hline D & 20(R)-Protopanaxatriol & $-\mathrm{H}$ & $-\mathrm{H}$ & $-H$ & Liao et al., 2008 \\
\hline E & Gingsenoside $\mathrm{RK}_{1}$ & $-G \mid c^{2}-1$ Glc & / & / & $\begin{array}{l}\text { Lau et al., 2004; } \\
\text { Wang et al., } 2012\end{array}$ \\
\hline E & Gingsenoside $\mathrm{Rs}_{5}$ & $-G c^{2}-{ }^{1} G \mid c^{6}-A c$ & / & / & Chan et al., 2007 \\
\hline $\mathrm{F}$ & Ginsenoside Rg5 & $-G \mid c^{2}-1 \mathrm{Glc}$ & / & / & $\begin{array}{l}\text { Lau et al., 2004; } \\
\text { Wang et al., } 2012\end{array}$ \\
\hline $\mathrm{F}$ & Ginsenoside $\mathrm{Rs}_{4}$ & $-G c^{2}-{ }^{1} G \mid c^{6}-A c$ & / & / & Chan et al., 2007 \\
\hline G & Gingsenoside $\mathrm{RK}_{3}$ & $-H$ & $-G l c$ & / & $\begin{array}{l}\text { Lau et al., 2004; } \\
\text { Wang et al., } 2012\end{array}$ \\
\hline G & Gingsenoside $\mathrm{Rg}_{6}$ & $-H$ & $-\mathrm{Glc}^{2}-{ }^{1} \mathrm{Rha}$ & / & Chan et al., 2007 \\
\hline G & $\begin{array}{l}3 \beta, 6 \alpha, 12 \beta \text {-Trihydroxydammar- } \\
20(21), 24 \text {-diene }\end{array}$ & $-H$ & $-H$ & / & Liao et al., 2008 \\
\hline
\end{tabular}

Structure skeletons and the positions of $R_{1}, R_{2}$, and $R_{3}$ please refer to Figure 1; Glc, $\beta$-D-glucopyranosyl; Rha, rhamnose; Ara(p), $\alpha$-L-Arabinose in pyranose form; Ara( $f$ ), $\alpha-L$-Arabinose in furanose form; XYl, xylose. 
The increasing content of 4 pairs of stereoisomeric saponins, i.e., $20(\mathrm{~S})-/ 20(\mathrm{R})-\mathrm{Rh}_{1}, 20(\mathrm{~S})-/ 20(\mathrm{R})-\mathrm{Rg}_{3}, \mathrm{Rk}_{3}$ and $\mathrm{Rh}_{4}$, and $\mathrm{RK}_{1}$ and $\mathrm{Rg}_{5}$, upon the extending of steaming and baking of notoginseng were reported (Wang et al., 2012). Two trans C20 dehydrated dammarane-type saponins, i.e., $\mathrm{Rh}_{4}$ and $\mathrm{Rg}_{5}$, were found to be of significantly higher contents compared with other 6 stereoisomeric saponins in processed notoginsengs. The contents of the two saponins reached $1 \%(\mathrm{w} / \mathrm{w})$ after the dry notoginseng was steamed in an autoclave at $120^{\circ} \mathrm{C}$ for $8 \mathrm{~h}$.

Chan et al. (2007) firstly introduced the name "biomarker" into steamed notoginseng. Here, the "biomarker" means the compounds only existed in steamed notoginseng or those of quite high content in steamed notoginseng while extremely low content in raw materials. Here, the biomarkers tentatively given in steamed notoginseng include 8 pairs of stereoisomeric saponins, i.e., ginsenoside $20(\mathrm{~S})-/ 20(\mathrm{R})-\mathrm{Rg}_{2}, 20(\mathrm{~S})-/ 20(\mathrm{R})-\mathrm{Rh}_{1}$, 20(S)-/20(R)- $\mathrm{Rg}_{3}, 20(\mathrm{~S})-/ 20(\mathrm{R})-\mathrm{Rs}_{3}, \mathrm{Rg}_{6}$ and $\mathrm{F}_{4}, \mathrm{Rk}_{3}$ and $\mathrm{Rh}_{4}$, $\mathrm{RK}_{1}$ and $\mathrm{Rg}_{5}$, and $\mathrm{Rs}_{5}$ and $\mathrm{Rs}_{4}$. Besides, ginsenoside 20(S)/20(R)-Rh 2 were also detected in steamed notoginseng, with quiet minor concentrations though. The concept of biomarker could be successfully used to differentiate raw and processed notoginseng.

Statically data has indicated that the content of 20 (S) $-\mathrm{Rg}_{3}$ in steamed notoginseng reaches its maximum after a $6 \mathrm{~h}$ steaming in an autoclave at $120^{\circ} \mathrm{C}$, and the prolongation of steaming time would not significantly increase the content of $20(\mathrm{~S})-\mathrm{Rg}_{3}$ anymore. However, in the case of $20(\mathrm{~S})-\mathrm{Rh}_{2}$, the steaming time should be extended to $24 \mathrm{~h}$ for the achievement of its maximum content (Toh et al., 2010). The structures of saponins newly generated in raw $P$. notoginseng are also summarized in Figure 1 and Table 1. In summary, there are one pair C-20 stereoisomers, i.e., $20(\mathrm{~S})-/ 20(\mathrm{R})-\mathrm{Rg}_{3}$, in raw notoginseng, and ten pairs of $\mathrm{C}$ 20 stereoisomers, including $20(\mathrm{~S})-/ 20(\mathrm{R})-\mathrm{Rg}_{3}, 20(\mathrm{~S})-/ 20(\mathrm{R})-\mathrm{Rh}_{2}$, 20(S)-/20(R)-Rh $, 20(\mathrm{~S})-/ 20(\mathrm{R})-\mathrm{Rg}_{2}, 20(\mathrm{~S})-/ 20(\mathrm{R})-\mathrm{Rs}_{3}, \mathrm{RK}_{2} / \mathrm{Rh}_{3}$, $\mathrm{Rg}_{6} / \mathrm{F}_{4}, \mathrm{Rk}_{3} / \mathrm{Rh}_{4}, \mathrm{RK}_{1} / \mathrm{Rg}_{5}$, and $\mathrm{Rs}_{5} / \mathrm{Rs}_{4}$ reported in processed P. notoginseng.
The mechanism of saponin transformations into sapogenins/prosapogenins in the steaming process has been extrapolated from the chemical structures of saponins, especially the changes in their sugar moieties. Under the steaming condition, the hydrolysis of the xylosyl residue attached to C-6 of notoginsenoside $\mathrm{R}_{1}$ and the hydrolysis of the rhamnosyl residue at C-6 of ginsenoside $\mathrm{Re}$ form ginsenoside $\mathrm{Rg}_{1}$. Ginsenoside $\mathrm{Rb}_{1}$ is hydrolyzed at the glucosyl residue at C-20 to yield ginsenoside $\mathrm{Rd} . \mathrm{Rg}_{1}$ and $\mathrm{Rd}$ are likely to be the parent compounds of newly formed saponins. The further hydrolysis of the glucosyl residue at $\mathrm{C}-20$ of $\mathrm{Rg}_{1}$ yields $\mathrm{Rh}_{1}$ which then forms $\mathrm{Rh}_{4}$ and $\mathrm{Rk}_{3}$ through dehydration at C-20. Similarly, the hydrolysation of the glucosyl residue at C-20 of $\mathrm{Rd}$ produces $\mathrm{Rg}_{3}$, and dehydration of $\mathrm{Rg}_{3}$ at C-20 yields $\mathrm{Rg}_{5}$ and $\mathrm{Rk}_{1}$, which are shown in Figure 2 (Wang et al., 2012).

\section{Determination Strategy for Saponin Stereoisomers}

As we all know, 20(S)- and 20(R)-ginsenoside epimers bear very similar molecular structures, and their fragment ions in mass spectra are the same. Recently, Qi et al. (2012) developed a LC-TOF-MS method to differentiate 20(S)- from 20(R)ginsenoside epimers based on the mass spectra in positive ion mode. In their study, a slight difference in the peak ratio of $\left[\mathrm{M}-2 \mathrm{H}_{2} \mathrm{O}+\mathrm{H}\right]^{+}$to $\left[\mathrm{M}-\mathrm{H}_{2} \mathrm{O}+\mathrm{H}\right]^{+}$has been found in these two epimers. Since the steric hindrance of 20(R)-epimer is greater than that of 20(S)-epimer during the dehydration at the C-20 hydroxyl group, the $\left[\mathrm{M}-2 \mathrm{H}_{2} \mathrm{O}+\mathrm{H}\right]^{+} /[\mathrm{M}-$ $\left.\mathrm{H}_{2} \mathrm{O}+\mathrm{H}\right]^{+}$ratio is higher for 20(S)-epimer (1:1) compared with $20(\mathrm{R})$-epimer $(0.7: 1)$. As the chemical features of $20(\mathrm{~S})$ and 20(R)-epimers are very close, the retention times of these two epimers might be overlapped according to the separation chromatographic columns. This identification method is of particular importance to distinguish 20(S)- from 20(R)-ginsenoside epimers.

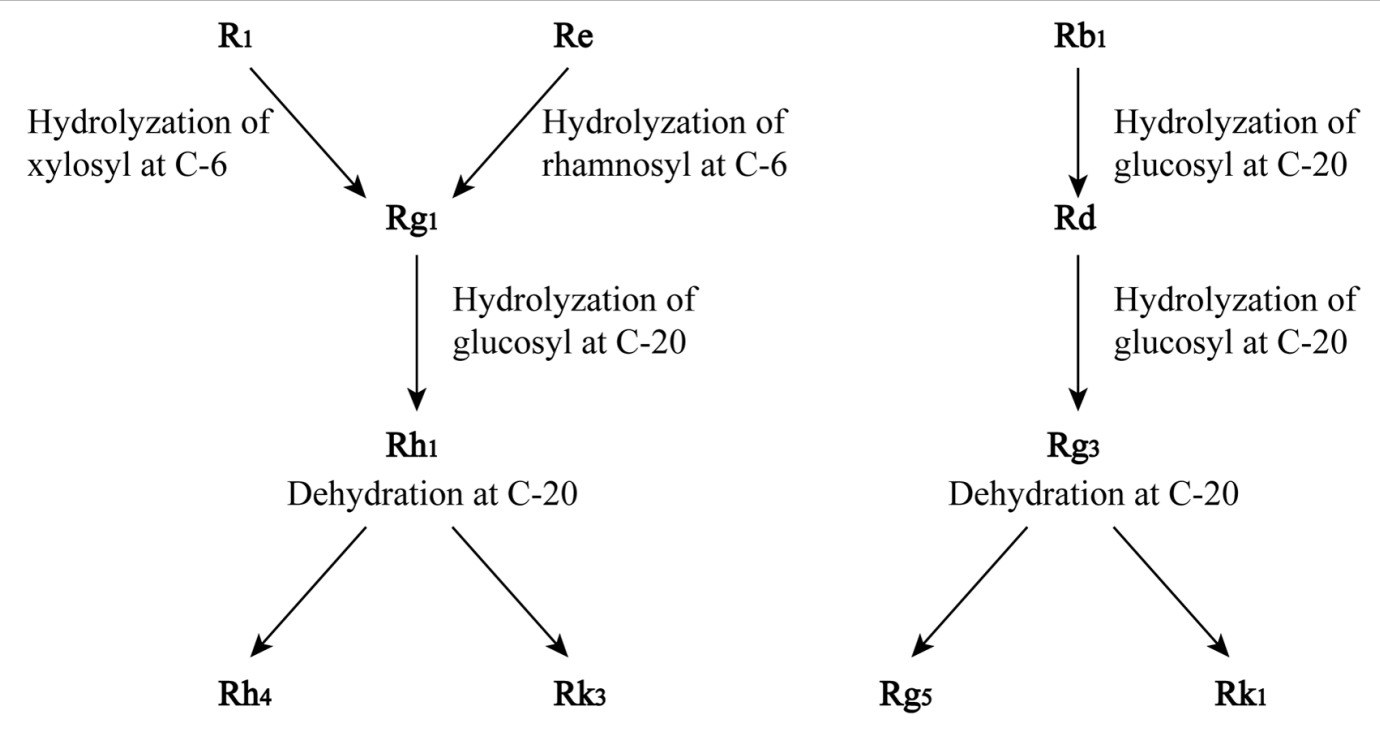

FIGURE 2 | Proposed transformation of saponins in the process of steaming of notoginseng. Adopted from Wang et al. (2012). 
One-dimensional and two-dimensional Nuclear Magnetic Resonance (NMR) spectroscopy is a very useful technique to distinguish the structures of stereoisomers of saponins. Specifically, ${ }^{13} \mathrm{C}$-NMR spectral data can provide information for structural elucidation of ginsenoside isomers. The chemical shifts of the characteristic peaks of 20(S)- and 20(R)- ginsenosides provide information for the identification of stereoisomers. In particular, the changes in chemical shift between 20(S)- and 20(R)-epimers at C-17, C-21 and C-22 in the ${ }^{13} \mathrm{C}-\mathrm{NMR}$ spectra are approximately $\Delta \delta\left(\delta_{S}-\delta_{R}\right)+4.1 \pm 0.1,+4.3 \pm 0.1$, and $-7.4 \pm 0.0$ ppm (Table 2) (Yang H. et al., 2014).

High Performance Liquid Chromatography (HPLC) is the most frequently employed separation method for the analysis of saponins stereoisomers. HPLC can be combined with different detection techniques such as ultraviolet detector (UV), diode array detection (DAD), evaporative light scattering detector (ELSD), mass spectrometry detector (MS) and charged aerosol detector (CAD). There are two main difficulties that researchers come across in performing HPLC-UV or HPLC-DAD analysis of saponin stereoisomers. Firstly, owing to their very similar structures, saponin stereoisomers could not be baseline separated on a simple isocratic eluted chromatographic condition by an ordinary reversed-phase C18 column. A chromatographic method with gradient elution program is often necessary, and the parameters of the appropriate chromatographic column, e.g., packing material, particle size, length, etc., should be selected elaborately; Secondly, since saponins don't possess aromatic groups, their UV absorptions are very low. Thus, only end absorption at around $200 \mathrm{~nm}$ could be chosen for UV or DAD detection. Therefore, ELSD, a universal and non-specific analytical detector, has been widely used in the detection of natural compounds including saponins. Firstly introduced in 2002, CAD, another universal detector for non-volatile and semivolatile compounds, has been used in the detection of saponins in notoginseng. Moreover, MS and tandem MS detector are often used when the elucidation of saponin structures is needed, or when very high sensitivity for the detection of analytes is required. MS detector is particularly important in the detection of saponins in biological matrices.

Gradient elution of water and acetonitrile has been regarded as the most widely used chromatographic conditions for HPLC-UV or DAD separation of saponin stereoisomers, since acetonitrile has a fairly strong eluting power and its cut-off wavelength is lower than $200 \mathrm{~nm}$, which makes it suitable for the detection at end absorption (Wang et al., 2008; Liu et al., 2010c; Dong et al., 2011; Park et al., 2013). In this case, UV wavelength is normally set at $203 \mathrm{~nm}$ for saponin determination. For ELSD and $\mathrm{MS}$ detectors, $\mathrm{CH}_{3} \mathrm{COOH}$ and $\mathrm{HCOOH}$ are usually added into mobile phases to assist a better volatilization of saponin analytes (Chan et al., 2007; Sun et al., 2009; Bae et al., 2013; Wan et al., 2013). Our group has developed a HPLC-CAD method to simultaneously separate 22 saponins existed in raw and processed notoginseng, in which 5 pairs of 20 (S)- and 20(R)ginsenoside epimers were separated (Peng et al., 2016b). In addition, using an appropriate column with small particle size can gain higher efficiency and better isolation. Ultra-performance liquid chromatography (UPLC), which utilizes silica particles of less than $2 \mu \mathrm{m}$, makes it possible to perform better separations in short periods of time (Chan et al., 2007; Park et al., 2013). The chromatographic conditions for simultaneous determination of stereoisomeric saponins are summarized in Table 3.

\section{Preparation of Saponin Stereoisomers}

As far as we know, major ginsenosides, e.g., $\mathrm{Rb}_{1}, \mathrm{Rb}_{2}, \mathrm{Rd}, \mathrm{Re}$, and $\mathrm{Rg}_{1}$, occupy $90 \%$ of total saponins which exist naturally in raw herbs. However, minor saponins, e.g., $\mathrm{Rg}_{3}, \mathrm{Rh}_{2}, \mathrm{Rg}_{2}, \mathrm{Rh}_{1}$, and $\mathrm{F}_{1}$, usually exert stronger pharmacological activities such as anti-tumor, antidiabetic, anti-oxidative, and anti-aging effects over the glycosylated major saponins (Choi et al., 2011; Kim Y.J. et al., 2013). A variety of technologies has been performed to produce minor saponins, and the processes include mild acid hydrolysis, alkali treatment and microbial conversions (Bae et al., 2002; Cheng et al., 2008; Cui et al., 2016). Ginsenoside $R b_{1}, R b_{2}, R c$ and $R d$ can be converted into a mixture of 20(S)- and 20(R)- $\mathrm{Rg}_{3}$ by either mild acid treatment or heating (Park, 2004). Nevertheless, side-reactions such as epimerization, hydration and hydroxylation are the disadvantages of chemical hydrolysis. Moreover, the optical purification from the mixture of 20(S)- and 20(R)-ginsenoside mixture is a time-consuming task. Fortunately, microorganic and enzymatic hydrolysis from major saponins has been found to be stereoselective and regarded as an efficient technology to avoid those side-reactions mentioned above (Liu et al., 2010c). Another advantage of this method is that the 20(S)-epimer produced would not transform to their 20(R)-epimer during the course of the reaction. Aspergillus niger obtained from soil shows a strong and stereoselective ability to transform $\mathrm{Rg}_{3}(\mathrm{~S}, \mathrm{R})$ into $\mathrm{PPD}(\mathrm{S}, \mathrm{R})$ completely. Microbacterium sp. GS514 isolated and identified from soil of a ginseng field exhibits a strong capability to convert ginsenoside $\mathrm{Rb}_{1}$ to $20(\mathrm{~S})$ $\mathrm{Rg}_{3}$ (Cheng et al., 2008). A new ginsenoside-transformingglucosidase (BglQM) from Mucilaginibacter sp. Strain QM49 efficiently transforms ginsenoside $\mathrm{Re}$ and $\mathrm{Rg}_{1}$ into $20(\mathrm{~S})-\mathrm{Rg}_{2}$ and $20(\mathrm{~S})-\mathrm{Rh}_{1}$, respectively (Cui et al., 2013b). Moreover, Du et al. (2014) reported a method to transform $\operatorname{Re}$ to 20(S)$\mathrm{Rg}_{2}$ with the aid of Pseudonocardia sp. Gsoil 1536, which can produce high-purity $20(\mathrm{~S})-\mathrm{Rg}_{2}$ in a $100 \mathrm{~g}$ scale. Various saponinhydrolyzing pathways to produce stereoisomeric saponins from major saponins by enzymatic hydrolysis are summarized in Table 4 for practical application.

\section{PHARMACOLOGY}

\section{Pharmacological Difference Between Raw and Processed $P$. notoginseng}

In traditional Chinese medical applications, processed notoginseng is distinguished from raw notoginseng by the claim of its capability to "nourish" blood (Medicine SAoTC, 1996). So far, not many contemporary researches have been performed to focus on the pharmacological difference between these two types of herbs, however, some research reports have still revealed that processed notoginseng exhibit more potent pharmaceutical activities than raw notoginseng, such as anticancer, antiplatelet and anticoagulant, and platelet aggregation inhibition effects, etc. 
TABLE 2 | ${ }^{13} \mathrm{C}-\mathrm{NMR}$ spectroscopic data for compounds 20(S)-/(R)- $-\mathrm{Rg}_{3}, 2 \mathrm{O}(\mathrm{S})-/(\mathrm{R})-\mathrm{Rh} 2,2 \mathrm{O}(\mathrm{S}-) /(\mathrm{R})-\mathrm{Rh}_{1}, 20(\mathrm{~S})-/(\mathrm{R})-\mathrm{Rg}_{2}$ in pyridine-d5.

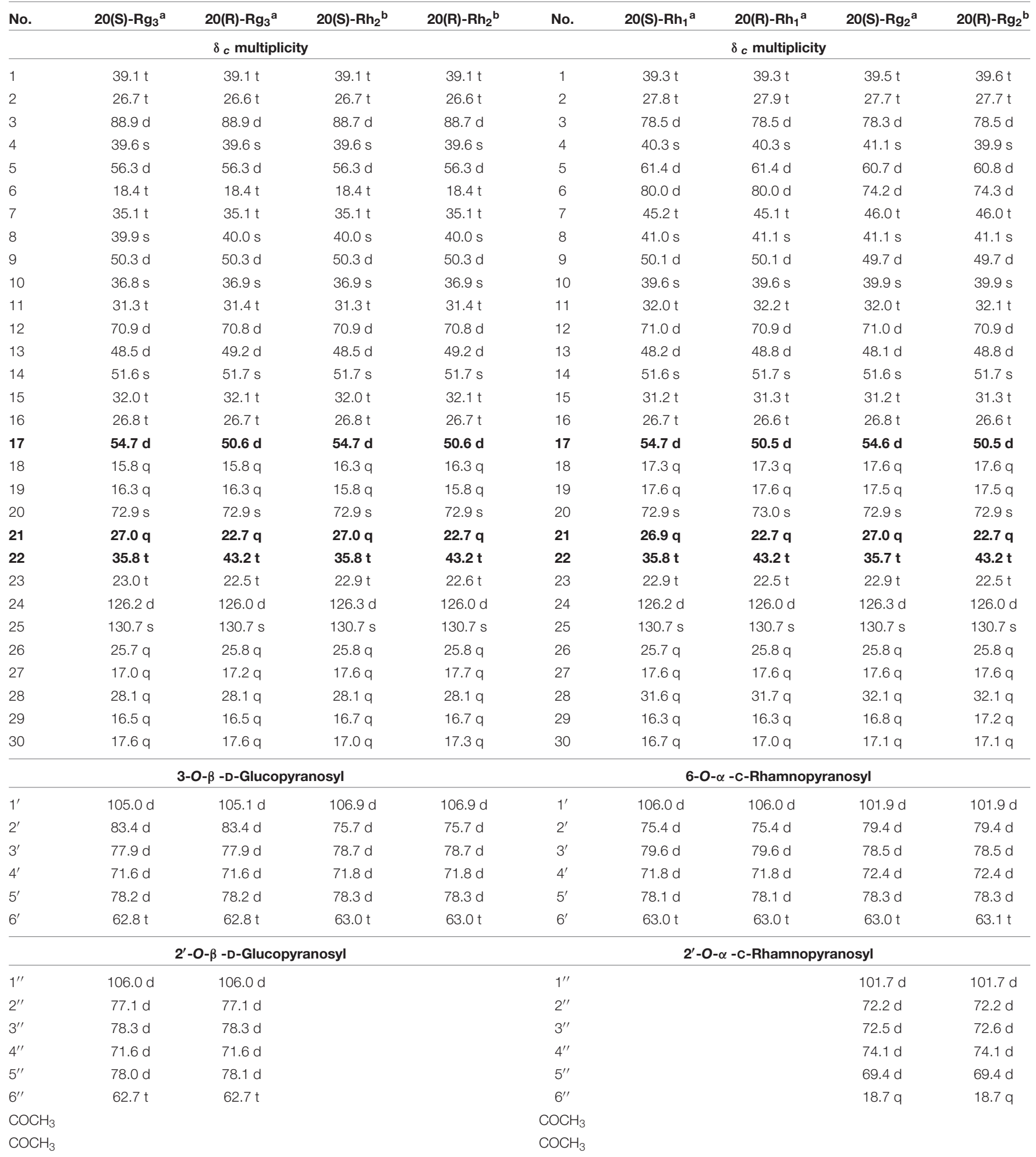

Multiplicity of ${ }^{13} \mathrm{C}-\mathrm{NMR}$ data determined by distortionless enhancement by polarization transfer (DEPT) experiments. ${ }^{13} \mathrm{C}-\mathrm{NMR}$ data of this compound was measured at $125 \mathrm{MHz}$ and ${ }^{b}{ }^{13} \mathrm{C}-\mathrm{NMR}$ data of this compound was measured at $150 \mathrm{MHz}$. The bold values are the ${ }^{13} \mathrm{C}-\mathrm{NMR}$ spectra of $\mathrm{C}-17, \mathrm{C}-21$ and $\mathrm{C}-22$ that particularly change in chemical shift between 20(S)- and 20(R)-epimers.

The letters "t, $d, s, q$ " means triplet peak, double peak, single peak and quadruple peak respectively. 
TABLE 3 | Chromatographic conditions for simultaneous determination of stereoisomeric saponins.

\begin{tabular}{|c|c|c|c|c|}
\hline Column & Mobile phase & Detector & $\begin{array}{l}\text { Stereoisomeric saponins } \\
\text { simultaneously separated }\end{array}$ & Reference \\
\hline $\begin{array}{l}\text { Zorbax Eclipse XDB-C18 } \\
(25 \mathrm{~cm} \times 4.6 \mathrm{~mm}, 5 \mu \mathrm{m})\end{array}$ & $\begin{array}{l}\mathrm{A}: \mathrm{H}_{2} \mathrm{O}, \mathrm{B}: \mathrm{CH}_{3} \mathrm{CN} \text {; } \\
\text { gradient elution }\end{array}$ & UV, 203 nm & $\begin{array}{l}20(\mathrm{~S})-/ 20(\mathrm{R})-\mathrm{Rg}_{2}, 20(\mathrm{~S})-/ 20(\mathrm{R})-\mathrm{Rh}_{1} \\
20(\mathrm{~S})-/ 20(\mathrm{R})-\mathrm{Rg}_{3}, 20(\mathrm{~S})-/ 20(\mathrm{R})-\mathrm{Rh}_{2} \\
\mathrm{Rk}_{1} / \mathrm{Rg}_{5}, \mathrm{Rg}_{6} / \mathrm{F}_{4}, \mathrm{Rk}_{3} / \mathrm{Rh}_{4} \\
20(\mathrm{~S})-/ 20(\mathrm{R})-\mathrm{PPD}\end{array}$ & Dong et al., 2011 \\
\hline $\begin{array}{l}\text { Discovery C18 } \\
(25 \mathrm{~cm} \times 4.6 \mathrm{~mm}, 5 \mu \mathrm{m})\end{array}$ & $\begin{array}{l}\mathrm{A}: \mathrm{H}_{2} \mathrm{O}, \mathrm{B}: \mathrm{CH}_{3} \mathrm{CN} \text {; } \\
\text { gradient elution }\end{array}$ & UV, $203 \mathrm{~nm}$ & $\begin{array}{l}\text { 20(S)-/2O(R)- } R g_{3}, 20(S)-/ 20(R)-R h_{2}, \\
20(S)-/ 20(R)-P P D\end{array}$ & Liu et al., 2010c \\
\hline $\begin{array}{l}\text { ACQUITY BEH C18 } \\
(10 \mathrm{~cm} \times 2.1 \mathrm{~mm}, 1.7 \mu \mathrm{m})\end{array}$ & $\begin{array}{l}\text { A: } 0.001 \% \mathrm{H}_{3} \mathrm{PO}_{4} \\
\text { B: } 0.001 \% \mathrm{H}_{3} \mathrm{PO}_{4} \text { in } \mathrm{CH}_{3} \mathrm{CN} \text {; } \\
\text { gradient elution }\end{array}$ & DAD, 203 nm & $\begin{array}{l}20(\mathrm{~S})-/ 20(\mathrm{R})-\mathrm{Rg}_{2}, 2 \mathrm{O}(\mathrm{S})-/ 20(\mathrm{R})-\mathrm{Rg}_{3} \\
2 \mathrm{O}(\mathrm{S})-/ 20(\mathrm{R})-\mathrm{Rh}_{2}, \mathrm{Rk}_{1} / \mathrm{Rg}_{5}, \mathrm{Rg}_{6} / \mathrm{F}_{4} \\
\mathrm{Rk}_{3} / \mathrm{Rh}_{4}, \mathrm{RK}_{2} / \mathrm{Rh}_{3}\end{array}$ & Park et al., 2013 \\
\hline $\begin{array}{l}\text { Waters HSS C18 column } \\
(25 \mathrm{~cm} \times 4.6 \mathrm{~mm}, 3.5 \mu \mathrm{m})\end{array}$ & $\begin{array}{l}\mathrm{A}: \mathrm{H}_{2} \mathrm{O}, \mathrm{B}: \mathrm{CH}_{3} \mathrm{CN} \text {; } \\
\text { gradient elution }\end{array}$ & $\begin{array}{l}\text { CAD; } \\
\text { UV } 203 \mathrm{~nm}\end{array}$ & $\begin{array}{l}20(S)-/ 20(R)-R g_{2}, 20(S)-/ 20(R)-R h_{1}, \\
20(S)-/ 20(R)-R g_{3}, 20(S)-/ 20(R)-R h_{2}, \\
20(S)-/ 20(R)-P P D\end{array}$ & Peng et al., 2016b \\
\hline $\begin{array}{l}\text { Zorbax Eclipse XDB-C18 } \\
(25 \mathrm{~cm} \times 4.6 \mathrm{~mm}, 5 \mu \mathrm{m})\end{array}$ & $\begin{array}{l}\mathrm{A}: \mathrm{H}_{2} \mathrm{O}, \mathrm{B}: \mathrm{CH}_{3} \mathrm{CN} \text {; } \\
\text { gradient elution }\end{array}$ & UV 203 nm & $\begin{array}{l}20(\mathrm{~S})-/ 20(\mathrm{R})-\mathrm{Rg}_{2}, 20(\mathrm{~S})-/ 20(\mathrm{R})-\mathrm{Rg}_{3} \\
20(\mathrm{~S})-/ 20(\mathrm{R})-\mathrm{Rs}_{3}, \mathrm{Rk}_{1} / \mathrm{Rg}_{5}, \mathrm{Rg}_{6} / \mathrm{F}_{4} \\
\mathrm{RS}_{4} / \mathrm{Rh}_{5}\end{array}$ & Wang et al., 2008 \\
\hline $\begin{array}{l}\text { Discovery C18 } \\
(25 \mathrm{~cm} \times 4.6 \mathrm{~mm}, 5 \mu \mathrm{m})\end{array}$ & $\begin{array}{l}\mathrm{A}: \mathrm{CH}_{3} \mathrm{CN}-\mathrm{H}_{2} \mathrm{O}-5 \% \mathrm{CH}_{3} \mathrm{COOH} \\
(10: 85: 5) \\
\mathrm{B}: \mathrm{CH}_{3} \mathrm{CN}-\mathrm{H}_{2} \mathrm{O}(80: 20) ; \\
\text { gradient elution }\end{array}$ & $\begin{array}{l}\text { ELSD; } \\
\text { probe temperature: } \\
60^{\circ} \mathrm{C} \text {; } \\
\text { nebulizer flow: } \mathrm{N}_{2} \\
1.8 \mathrm{~L} / \mathrm{min}\end{array}$ & $\begin{array}{l}20(\mathrm{~S})-/ 20(\mathrm{R})-\mathrm{Rg}_{3}, 20(\mathrm{~S})-/ 20(\mathrm{R})-\mathrm{Rs}_{3} \\
\mathrm{Rg}_{6} / \mathrm{F}_{4}, \mathrm{Rk}_{3} / \mathrm{Rh}_{4}, \mathrm{Rk}_{1} / \mathrm{Rg}_{5}, \mathrm{RS}_{4} / \mathrm{Rh}_{5}\end{array}$ & Sun et al., 2009 \\
\hline $\begin{array}{l}\text { ACQUITY C18 } \\
(10 \mathrm{~cm} \times 2.1 \mathrm{~mm}, 1.7 \mu \mathrm{m})\end{array}$ & $\begin{array}{l}\text { A: } 0.001 \% \mathrm{HCOOH} \text {, } \\
\text { B: } 0.001 \% \mathrm{HCOOH} \text { in } \mathrm{CH}_{3} \mathrm{CN} \text {; } \\
\text { gradient elution }\end{array}$ & $\begin{array}{l}\text { TOF MS, ES+ and } \\
\text { ES- mode }\end{array}$ & $\begin{array}{l}20(\mathrm{~S})-/ 20(\mathrm{R})-\mathrm{Rg}_{2}, 20(\mathrm{~S})-/ 20(\mathrm{R})-\mathrm{Rh}_{1} \\
20(\mathrm{~S})-/ 20(\mathrm{R})-\mathrm{Rg}_{3}, 20(\mathrm{~S})-/ 20(\mathrm{R})-\mathrm{Rs}_{3} \\
\mathrm{~F}_{4} / \mathrm{Rg}_{6}, \mathrm{Rk}_{3} / \mathrm{Rh}_{4}, \mathrm{RK}_{1} / \mathrm{Rg}_{5}, \mathrm{Rs}_{5} / \mathrm{Rs}_{4}\end{array}$ & Chan et al., 2007 \\
\hline $\begin{array}{l}\text { Zorbax Extend C18 } \\
(25 \mathrm{~cm} \times 4.6 \mathrm{~mm}, 5 \mu \mathrm{m})\end{array}$ & $\begin{array}{l}\text { A: } 0.001 \% \mathrm{HCOOH} \text {, } \\
\text { B: } 0.001 \% \mathrm{HCOOH} \text { in } \mathrm{CH}_{3} \mathrm{CN} \text {; } \\
\text { gradient elution }\end{array}$ & QTOF MS, ESI- mode & $\begin{array}{l}20(S)-/ 20(R)-R g_{2}, 20(S)-/ 20(R)-R h_{1}, \\
20(S)-/ 20(R)-R g_{3}, 20(S)-/ 20(R)-R h_{2}, \\
F_{4} / R g_{6}, R K_{1} / R g_{5}\end{array}$ & Wan et al., 2013 \\
\hline $\begin{array}{l}\text { Acclaim RSLC C18 } \\
(15 \mathrm{~cm} \times 2.1 \mathrm{~mm}, 2.2 \mu \mathrm{m})\end{array}$ & $\begin{array}{l}\mathrm{A}: \mathrm{CH}_{3} \mathrm{CN}, \mathrm{B}: 0.1 \% \mathrm{HCOOH} \\
\text { gradient elution }\end{array}$ & $\begin{array}{l}\text { Tandem MS, ES- } \\
\text { mode }\end{array}$ & $20(\mathrm{~S})-/ 20(\mathrm{R})-\mathrm{Rg}_{3}, 20(\mathrm{~S})-/ 20(\mathrm{R})-\mathrm{Rh}_{2}$ & Bae et al., 2013 \\
\hline
\end{tabular}

Compared with raw $P$. notoginseng, steamed $P$. notoginseng is found to be more potent in antiplatelet and anticoagulant effects in vitro. Moreover, it also exhibites stronger platelet aggregation inhibition effects ex vivo, and the effects could be enhanced along with the prolongation of steaming duration (Lau et al., 2009). A colorimetric WST-1 assay has been performed to evaluate the anti-proliferative effects of raw and steamed $P$. notoginseng on three human liver cancer cells, i.e., SNU449, SNU182 and HepG2. Results have indicated that steamed $P$. notoginseng presents higher anti-proliferative effects against these three types of liver cancer cells. Besides, the anti-proliferative effects of 5 originally existed saponins in raw P. notoginseng, i.e., $\mathrm{Rg}_{1}, \mathrm{Rb}_{1}, \mathrm{Rd}, \mathrm{Re}$ and $\mathrm{R}_{1}$, as well as 4 newly produced saponins in steamed $P$. notoginseng, i.e., $\mathrm{Rh}_{2}, \mathrm{Rk}_{1}$, $\mathrm{Rk}_{3}$ and $20(\mathrm{~S})-\mathrm{Rg}_{3}$ have also been assessed. Not surprisingly, $\mathrm{Rk}_{3}, \mathrm{Rh}_{2}, \mathrm{Rk}_{1}$ and $20(\mathrm{~S})-\mathrm{Rg}_{3}$ exhibits more anti-proliferative effects compared with the original saponins (Toh et al., 2011). Moreover, the extract of steamed notoginseng is effective in the inhibition of proliferation of SW-480 human colorectal cancer cells. Meanwhile, the comparison results of the proliferation effects between ginsenoside $\mathrm{Rg}_{1}, \mathrm{Rb}_{1}$ and $\mathrm{Rg}_{3}$ shows that the newly generated ginsenoside $\mathrm{Rg}_{3}$ is the most potent saponin on the antiproliferative activities on SW-480 human colorectal cancer cells (Sun et al., 2010). This anticancer effect of steamed
P. notoginseng was further confirmed by MTS method and flow cytometry (Sun et al., 2011).

Apparently, the difference of compound basis between raw and processed $P$. notoginseng directly influences their pharmacological activities. With the prolongation of processing duration, quite a few secondary saponins which are not naturally occurred in raw herbs are gradually generated in $P$. notoginseng. What should be emphasized is that most of the newly occurred saponins are stereoisomers, which exhibit quite potent biological activities. That explains why processed $P$. notoginseng exhibit distinct pharmacological behaviors compared with raw herbs.

\section{Stereospecific Pharmacological Effects of $20(\mathrm{~S})-$ and $\mathbf{2 0}(\mathrm{R})-\mathrm{Rg}_{3}$}

Ginsenoside $\mathrm{Rg}_{3}$ is one of the most biologically potent saponins in $P$. notoginseng, which exerts a wide scope of pharmacological actions, e.g., anti-inflammatory (Park et al., 2012), anti-tumor (Kim Y.-J. et al., 2014), antioxidant (Wei et al., 2012b), anti-diabetic (Ju et al., 2012; Kim S.S. et al., 2014), and neuroprotective (Lee B. et al., 2013) activities. Extensive research have revealed that ginsenoside $\mathrm{Rg}_{3}$ displays a wide spectrum of anticancer activities in the treatment of colon, lung (Kim Y.J. et al., 2014), breast (Kim B.-M. et al., 2014), hepatic (Lee J.Y. et al., 2013), pancreatic (Guo et al., 2014) cancer and 
TABLE 4 | Major saponins stereoisomers transformations by glycoside hydrolases.

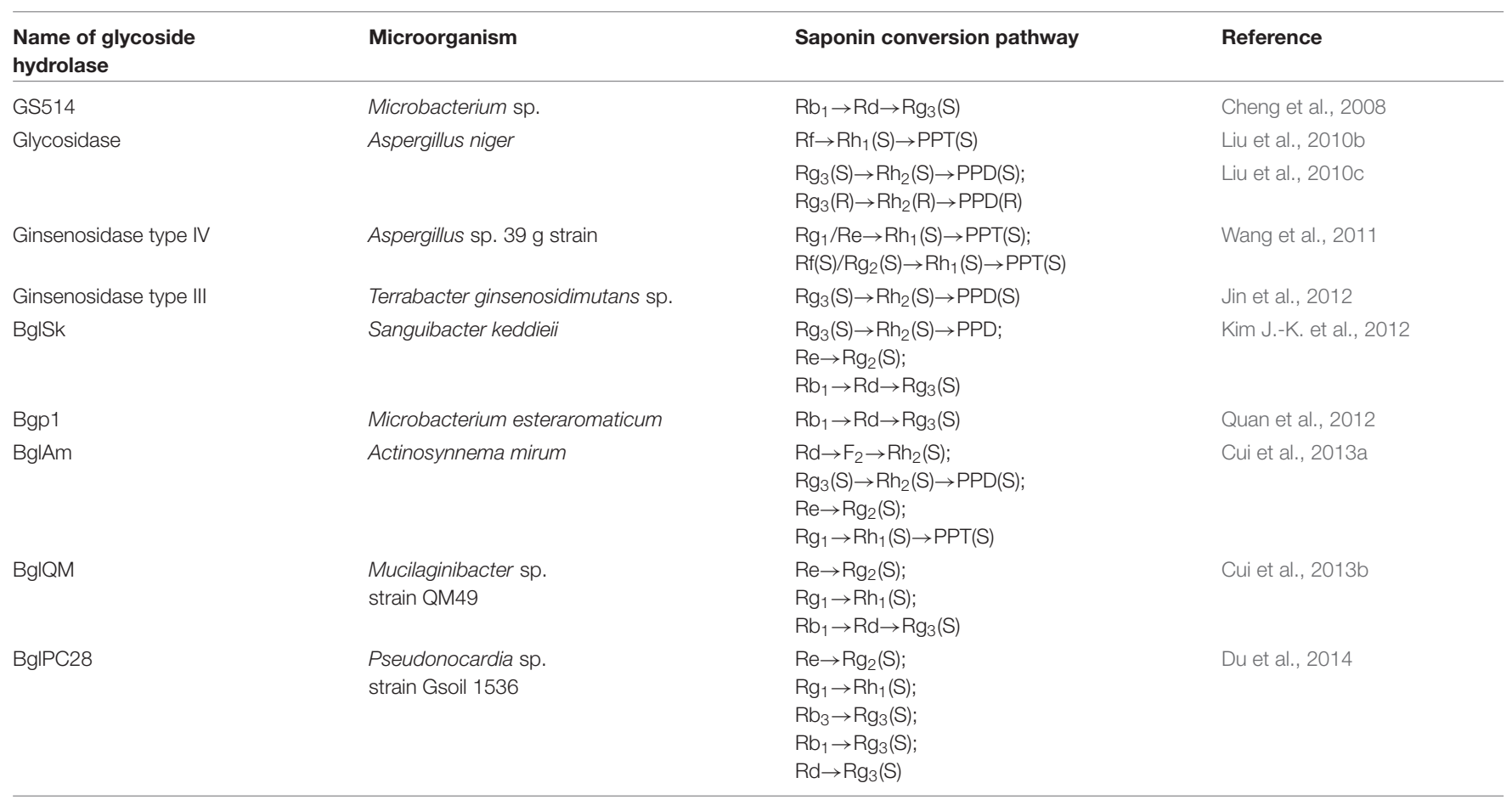

melanoma (Shan et al., 2015), via the mechanism of promoting cancer cell apoptosis, as well as inhibiting cell proliferation, metastasis and invasion. In addition, ginsenoside $\mathrm{Rg}_{3}$ has also been demonstrated to be a beneficial supplement in the enhancement of the inhibitory effects on chemotherapy (Sun et al., 2016).

At the early stages of pharmacological researches on this ginsenoside, the optical conformation was not specified, and the mixture of $20(\mathrm{~S})$ - and $20(\mathrm{R})-\mathrm{Rg}_{3}$ epimers has often been studied since very little information was obtained on their stereoselective differences in pharmacological actions (Choi et al., 2011). However, recent investigations have revealed that this pair of ginsenoside $\mathrm{Rg}_{3}$ stereoisomers exhibits a diversity of stereoselective activities, such as relaxation of coronary artery contractions, regulation of ion channel, effects on immune system, as well as anti-tumor, neuro-protective, anti-oxidant and antidiabetic activities, based on the chiral center at C-20 in their molecular structures.

\section{Effects on Cardiovascular System}

Ginsenoside $\mathrm{Rg}_{3}$ has potent pharmacological activities in cardiovascular systems. Stereospecific activities of $\mathrm{Rg}_{3}$ epimers have been discovered on coronary artery relaxation, endothelial cells survival, and platelet anti-aggregation, etc.

Investigations on swine coronary artery have revealed that $20(\mathrm{~S})-\mathrm{Rg}_{3}$, but not $20(\mathrm{R})-\mathrm{Rg}_{3}$, engenders an effective coronary artery relaxation induced by $25 \mathrm{mM} \mathrm{KCl}$, which is concentration dependent yet endothelium independent. Moreover, although both $\mathrm{Rg}_{3}$ epimers could induce a significant, concentrationdependent relaxation of coronary artery contractions in intact samples induced by $3 \mathrm{mM} 5-\mathrm{HT}$, only $20(\mathrm{~S})-\mathrm{Rg}_{3}$ inhibits coronary artery contraction in endothelium-denuded arteries. The stereospecific effects are probably owing to the inhibition of L-type $\mathrm{Ca}^{2+}$ channel or the elevation of $\mathrm{Ca}^{2+}$ level in the cells induced by 5 -HT receptors (Kim et al., 2006). 20(S)- $\mathrm{Rg}_{3}$ has been found to show anti-apoptotic activity in human endothelial cells through Akt-dependent inhibition of the mitochondrial apoptotic signaling pathway. $20(\mathrm{~S})-\mathrm{Rg}_{3}$ has been shown to be comparable to $20 \mathrm{ng} / \mathrm{ml}$ of vascular endothelial growth factor (VEFG) on the promotion ability of endothelial cells survival, however, $20(\mathrm{R})-\mathrm{Rg}_{3}$ only exhibits very little activity (Min et al., 2006). Moreover, Lee et al. (2009) investigated the anti-platelet aggregation activities of $\mathrm{Rg}_{3}$ epimers, and results showed that $20(\mathrm{~S})-\mathrm{Rg}_{3}$ strongly inhibited arachidonic acid-induced platelet aggregation, while $20(\mathrm{R})-\mathrm{Rg}_{3}$ inhibited collagen-induced platelet aggregation.

\section{Anti-tumor Effects}

Quite a few researches have indicated that both 20(S)- and 20(R)$\mathrm{Rg}_{3}$ exhibit anti-tumor activities, which have received much attention in recent investigations. Nevertheless, it is hard to say which stereoisomer exhibit higher anti-tumor activities based on available literatures so far, as these two compounds may function differently in different cell lines.

20 (S) $-\mathrm{Rg}_{3}$ stereospecifically induces angiogenesis by promoting human endothelial cells proliferation, migration and tube formation in vitro, and endothelial sprouting ex vivo at a micromolar concentration level (Kwok et al., 2012). It is identified to be the main active component with anticancer effects on human gastric cancer AGS cells, while $20(\mathrm{R})-\mathrm{Rg}_{3}$ has no effect (Park et al., 2014). Moreover, 20(S)- $\operatorname{Rg}_{3}$ is also found to be effective in other cell lines, such as human leukemic U937 
A
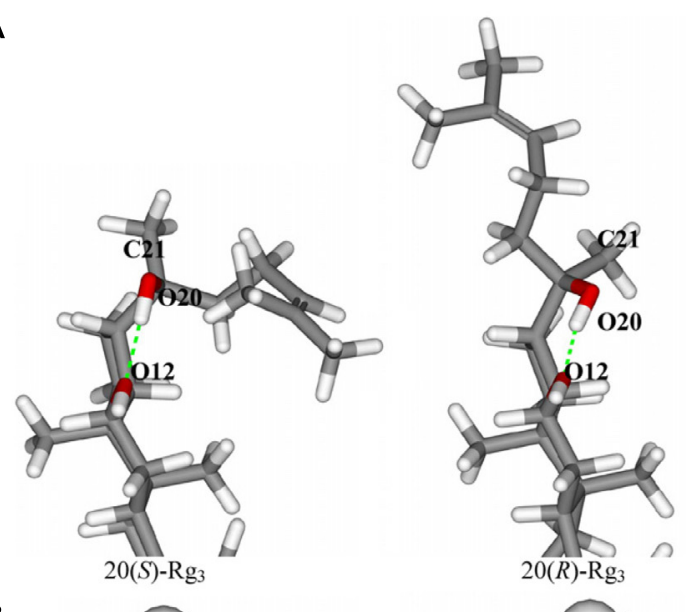

B

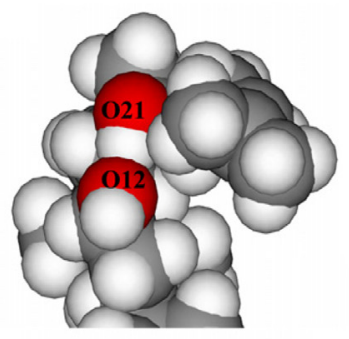

C

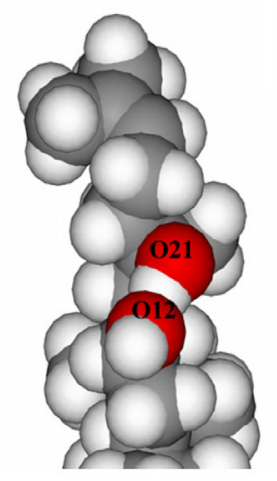

y $90^{\circ}$

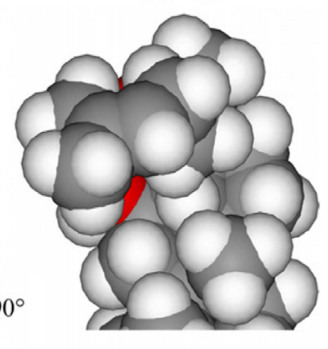

$+1$

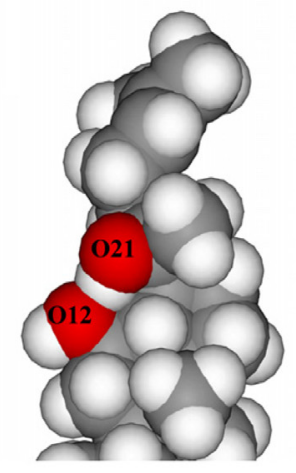

FIGURE 3 | (A) Hydrogen bonds between HO20 and 012 in 20(S)- and 20(R)-Rg3. (B) Space filling representation of 20(S)-Rg . (C) Space filling representation of 20(R)- $\mathrm{Rg}_{3}$ (adopted from Kang et al., 2005).

and HL-60 cells (Qiu et al., 2014), multiple myeloma U266 cells (Song et al., 2014a), human ovarian cancer HO-8910 (Wang et al., 2014) and A2780 cells (Park et al., 2016), and colon cancer HT-29 cells (Yuan et al., 2010).

However, 20(R)- $\mathrm{Rg}_{3}$ shows a stronger anti-tumor effect on the inhibition of $\mathrm{H} 22$ transplanted tumors growth, as well as a higher immunomodulatory activity on H22-bearing mice, compared with its 20 (S)-epimer, which may be attributed to its ability to stimulate lymphocyte proliferation and elevate cytokine levels in tumor-bearing mice (Wu et al., 2014). Furthermore, the comparison of the effects between 20(S)- and 20(R)- $\operatorname{Rg}_{3}$ on epithelial-mesenchymal transition (EMT) reveal that 20(R)$\mathrm{Rg}_{3}$, but not 20(S)- $\mathrm{Rg}_{3}$, markedly increases the expression of the epithelial marker $E$-cadherin and represses Snail upregulation and the expression of the mesenchymal marker vimentin

during the initiation of the TGF- $\beta 1$-induced EMT. 20 (R)-Rg also inhibits the TGF- $\beta 1$-induced increasing in cell migration, invasion, and anoikis resistance of A549 lung cancer cells (Kim Y.-J. et al., 2014).

\section{Effects on Ion Channel Current}

$20(\mathrm{~S})$ - and 20(R)- $\mathrm{Rg}_{3}$ epimers are reported to exhibit stereospecific actions in ion channels, including $\mathrm{Ca}^{2+}, \mathrm{K}^{+}$, and $\mathrm{Na}^{+}$(Kang et al., 2005; Lee et al., 2007). Without exception, $20(\mathrm{~S})-\mathrm{Rg}_{3}$, but not $20(\mathrm{R})-\mathrm{Rg}_{3}$, has been demonstrated to significantly inhibit these channel currents in a dose- and voltage-dependent manner. The ${ }^{1} \mathrm{H}$ and ${ }^{13} \mathrm{C}$ NMR chemical shifts of all hydroxyl protons and the conformation of the tertiary structures of $20(\mathrm{~S})$ - and $20(\mathrm{R})-\mathrm{Rg}_{3}$ epimers indicates that a more potent interaction might be occurred between $20(\mathrm{~S})-\mathrm{Rg}_{3}$ with the receptor sections in ion channels compared with $20(\mathrm{R})-\mathrm{Rg}_{3}$, probably due to the deduction that the hydroxyl group of $20(\mathrm{~S})-\mathrm{Rg}_{3}$ on $\mathrm{C}-20$ may be geometrically better disposed to the hydroxyl receptor region in those ion channels. Moreover, $20(\mathrm{~S})-\mathrm{Rg}_{3}$ is more efficient on the regulation of mutant 5-HT3A receptor channel activity (Lee et al., 2007). It can be inferred that $20(\mathrm{~S})-\mathrm{Rg}_{3}$ might be a useful agent for regulation of ion channel current, which could be used for the treatment of coronary artery and neuron system disease. For instance, the neuro-protection mechanism and antinociceptive effects on inflammation of $20(\mathrm{~S})-\mathrm{Rg}_{3}$ is via the mechanism of regulating channels and receptors (Park et al., 2012; Kang et al., 2013).

\section{Effects on Immune System}

Several studies have highlighted the stereospecific effects of ginsenoside $\mathrm{Rg}_{3}$ in immune system. Wei et al. (2012a) utilized ovalbumin (OVA) as a model to assess the adjuvant effects of $20(\mathrm{~S})-/ 20(\mathrm{R})-\mathrm{Rg}_{3}$ epimers. Results showed that $20(\mathrm{R})-\mathrm{Rg}_{3}$ exhibit higher adjuvant effects on OVA induced immune system in mice. Another study has compared the effects of these two epimers on the growth of hepatocellular carcinoma H22 transplanted tumors and the immune function of H22-bearing mice. And 20(R)-Rg has been found to be stereo-specifically inhibiting H22 tumor growth in vivo at least partly by improving the host's cellular immunity, which means that this 20(R)-epimer is clinically more potent in the treatment of immune-mediated diseases (Wu et al., 2014). Interestingly, although $20(\mathrm{~S})-\mathrm{Rg}_{3}$ exhibits many potent activities in other clinical treatments, $20(\mathrm{R})-\mathrm{Rg}_{3}$ seems to be a better epimer for the treatment of immune disorders based on the literature so far.

\section{Antidiabetic Effects}

To explore the difference of ginsenoside $\mathrm{Rg}_{3}$ epimers in antidiabetic effects, glucose-stimulated insulin secretion and phosphorylation of AMPK were examined in HIT-T15 and C2C12 myotubes, respectively. $5 \mathrm{mM}$ of $20(\mathrm{~S})-\mathrm{Rg}_{3}$ enhanced insulin secretion to an extent comparable to $5 \mathrm{mM}$ glipizide (58 and $61 \%$ increments), but $20(\mathrm{R})-\mathrm{Rg}_{3}$ did not show any significant effect. In $\mathrm{C} 2 \mathrm{C} 12$ myotubes, although both of these two epimers significantly promoted the phosphorylations of AMPK and acetyl-CoA carboxylase (ACC), 20(R)- $\mathrm{Rg}_{3}$ showed a little less effect. These results indicate that $20(\mathrm{~S})-\mathrm{Rg}_{3}$ might be a more 
TABLE 5 | Brief contrast of the pharmacological effects of ginsenoside $\mathrm{Rg}_{2}$ and $\mathrm{Rh}_{2}$ stereoisomers.

\begin{tabular}{|c|c|c|c|c|}
\hline Name & Stereo-center & Pharmacological effects to be compared & $\begin{array}{l}\text { Stereoisomer with } \\
\text { more potent } \\
\text { activities }\end{array}$ & Reference \\
\hline Ginsenoside $\mathrm{Rg}_{2}$ & $20(\mathrm{~S}) / 20(\mathrm{R})$ & Inhibition of catecholamine secretion & $20(S)-\mathrm{Rg}_{2}$ & Kudo et al., 1998 \\
\hline \multirow[t]{7}{*}{ Ginsenoside $\mathrm{Rh}_{2}$} & $20(\mathrm{~S}) / 20(\mathrm{R})$ & Skin anti-photoaging activities & $20(\mathrm{~S})-\mathrm{Rh}_{2}$ & Oh et al., 2014 \\
\hline & & Inhibition of osteoclastgenesis in RAW264 cells & $20(\mathrm{R})-\mathrm{Rh}_{2}$ & Liu J. et al., 2009 \\
\hline & & Inhibition of prostate cancer cells proliferation & $20(S)-\mathrm{Rh}_{2}$ & Liu et al., 2010a \\
\hline & & Induction of apoptosis in human lungadenocarcinoma A549 cells & $20(\mathrm{~S})-\mathrm{Rh}_{2}$ & Zhang et al., 2011 \\
\hline & & $\begin{array}{l}\text { Anti-inflammatory, antioxidative and matrix metalloproteinase } \\
\text { inhibitory activities in the LPS-stimulated murine RAW264.7 } \\
\text { macrophage cells }\end{array}$ & $20(R)-R_{2}$ & Choi et al., 2013 \\
\hline & & Inhibiting of erythroleukemia K562 cells proliferation & $20(S)-\mathrm{Rh}_{2}$ & Xia et al., 2014 \\
\hline & & Inhibition of aldose reductase & $20(S)-R_{2}$ & Fatmawati et al., 2014 \\
\hline
\end{tabular}

potent anti-diabetic agent (Park et al., 2008). The antidiabetic activities of $20(\mathrm{~S})-\mathrm{Rg}_{3}$ have further been demonstrated, and the mechanisms on the treatment of diabetic renal damage and type 2 diabetes have been elucidated on this compound (Ju et al., 2012).

\section{Anti-oxidant and Anti-photoaging Effects}

$20(\mathrm{R})-\mathrm{Rg}_{3}$ has been found to be a more potent antioxidant compound than $20(\mathrm{~S})-\mathrm{Rg}_{3} .20(\mathrm{R})-\mathrm{Rg}_{3}$ significantly inhibites oxidative stress in mice induced by cyclophosphamide based on the parameters of spleen and thymus, total antioxidant capacity, the activities of catalase, superoxidase dismutase, lysozyme, xanthine oxidase as well as the levels of malondialdehyde and nitric oxide (Wei et al., 2012b). Nevertheless, 20(S)$\mathrm{Rg}_{3}$, but not $20(\mathrm{R})-\mathrm{Rg}_{3}$, has been investigated to decrease intracellular reaction oxygen species (ROS) levels induced by UV-B in human keratinocyte HaCaT cells and human dermal fibroblast cells, respectively. Moreover, 20(S)- $\mathrm{Rg}_{3}$ exhibites UV-B-induced matrix metalloproteinase (MMP)-2 inhibition activities in $\mathrm{HaCaT}$ cells, while $20(\mathrm{R})-\mathrm{Rg}_{3}$ does not (Lim et al., 2014). Although both $20(\mathrm{~S})-$ and $20(\mathrm{R})-\mathrm{Rg}_{3}$ may exhibit high anti-oxidant activities, the results are not contradictory. The experimental design of different animal models and cell lines may lead to different conclusions based on diverse therapeutic targets. Thus, further researches should be performed to elucidate the underlying mechanisms of these two stereoisomers.

\section{Stereospecific Effects of Other Saponin Stereoisomers}

Except for ginsenoside $\mathrm{Rg}_{3}$, other stereoisomeric saponins have also been found to exhibit stereospecific pharmacological activities. For example, $20(\mathrm{~S})-/ 20(\mathrm{R})-\mathrm{Rh}_{2}$, the metabolites of $20(\mathrm{~S})-/ 20(\mathrm{R})-\mathrm{Rg}_{3}$, have also been studied on the stereospecific effects in their antitumor, anti-photoaging, anti-inflammatory, antioxidative, matrix metalloproteinase inhibitory and osteoclastgenesis inhibitory effects (Liu J. et al., 2009; Choi et al., 2013; Fatmawati et al., 2014; Oh et al., 2014). Compared with $20(\mathrm{R})-\mathrm{Rh}_{2}, 20(\mathrm{~S})-\mathrm{Rh}_{2}$ exhibits stronger anticancer effects on prostate cancer cells and human lung adenocarcinoma A549 cells (Liu et al., 2010a; Zhang et al., 2011). Moreover, the inhibitory effects of $20(\mathrm{~S})-\mathrm{Rg}_{2}$ on catecholamine secretion are slightly greater than those of 20(R)- $\operatorname{Rg}_{2}$ (Kudo et al., 1998).
These results reveal that the structural difference between saponin stereoisomers may lead to significant distinctions in pharmacological activities, and this phenomenon should be carefully considered in the future development of saponin-based therapeutics. Brief contrast of the pharmacological effects of stereoisomeric saponins with their corresponding stereoisomers is given in Table 5 .

\section{Pharmacological Effects of Other Stereoisomeric Saponins}

Except for optical saponin epimers, geometric saponin epimers generated after the processing of $P$. notoginseng also exhibit high pharmacological activities, although the stereospecific effects have not been studied. For example, gingsenoside $\mathrm{RK}_{1}$ has been proved on its anti-platelet aggregation, anti-tumor, and vascular leakage blocking activities (Kim J.S. et al., 2012; Kim S.S. et al., 2014; Maeng et al., 2013). Gingsenoside $\operatorname{Rg}_{5}$, the geometric isomer of $\mathrm{RK}_{1}$, is shown to possess anti-inflammatory effects (Lee Y.Y. et al., 2013). Moreover, $\mathrm{Rg}_{5}$ and $\mathrm{Rh}_{3}$ can protect memory deficits induced by scopolamine (Kim E.-J. et al., 2013). Gingsenoside $\mathrm{RK}_{3}$ is capable to prevent apoptosis induced by hypoxia-reoxygenation in H9c2 cardiomyocytes (Sun et al., 2013).

The potent pharmacological activities of stereoisomeric saponins, which are mostly generated and acting as biomarkers in processed $P$. notoginseng, very well explain the pharmacological differences between the raw and processed herbs. Hence, the pharmacological behaviors of processed $P$. notoginseng are the combination of pharmacological activities of all the secondary saponins, which conforms to the theory of multi component multi targets of traditional Chinese medical drugs.

\section{Mechanism of Stereospecific Properties Between Saponin Stereoisomers}

Based on the above reports, a diversity of pharmacological differences has been discovered in saponin stereoisomers. Unfortunately, very few studies have been investigated on the mechanism of this interesting phenomenon at a molecular level by far. Apparently, the position of the hydroxyl group on C-20 plays an important role on the different activities of stereoisomers 
A

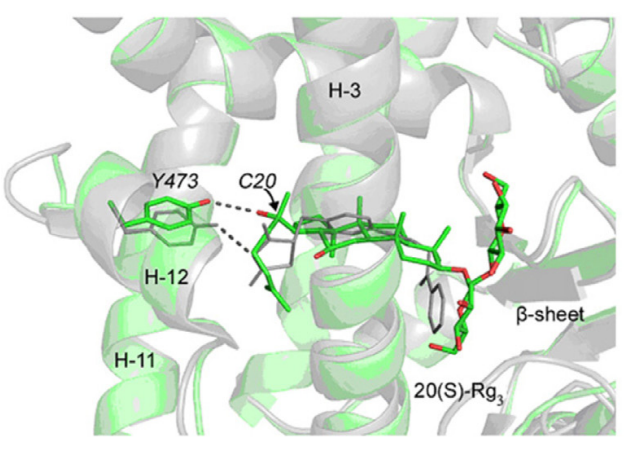

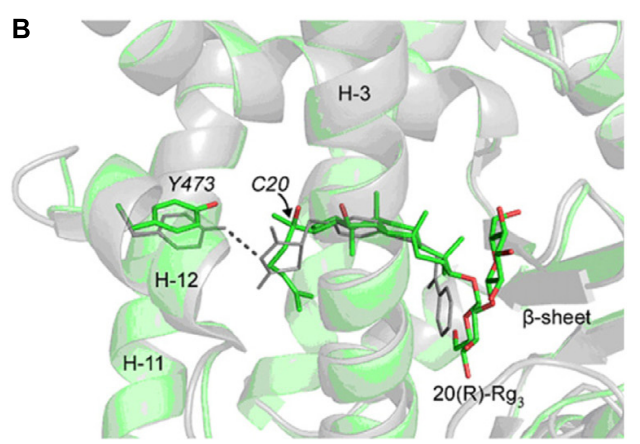

FIGURE 4 | Docking structures of 20(S)- $\mathrm{Rg}_{3}$ and 20(R)-Rg3 in the LBD of PPAR $\gamma$. The ginsenosides and the side chain of Tyr473 in helix-12 (H-12) are shown in sticks. Crystal structure of rosiglitazone in PPAR $\gamma$ (PDB:1ZGY) is superimposed and shown in gray for comparison. (A) The docked 20(S)-Rg 3 adopts a position similar of rosiglitazone in the protein and the hydroxyl group at the $\mathrm{C} 20$ position interacts with the side chain of $\mathrm{Ty} 473$ (dotted line). (B) The docked $20(\mathrm{R})-\mathrm{Rg}_{3}$ occupies similar position as the $20(\mathrm{~S})-\mathrm{Rg}_{3}$ in the protein but only the methyl group at the C20 position points toward Tyr473 and does not form any effective hydrogen bond. The protein backbones are rendered as faded out ribbons. Hydrogen atoms are not shown for clarity. Both $\mathrm{Rg}_{3}$ stereoisomers were docked into the protein by using Autodock 4.0, while the receptor protein structure is directly obtained from the protein databank (adopted from Kwok et al., 2012).

TABLE 6 | The main pharmacokinetic parameters of $20(\mathrm{~S})-\mathrm{Rg}_{3}$ and $20(\mathrm{R})-\mathrm{Rg}_{3}$ in rat plasma after intravenous and intra-gastric administration.

\begin{tabular}{|c|c|c|c|c|c|c|}
\hline Components & $\begin{array}{c}\text { Administration } \\
\text { Route }\end{array}$ & Dosage & $\mathbf{C}_{\max }$ & $\mathrm{T}_{\max }$ & $\begin{array}{c}\text { AUC } \\
(h * n g / m l)\end{array}$ & $t_{1 / 2}(h)$ \\
\hline $20(S)-\mathrm{Rg}_{3}$ & i.v. & $5 \mathrm{mg} / \mathrm{kg}$ & $70096.2 \pm 7204.6$ & 0.033 & $39591.8 \pm 1800.0$ & $4.7 \pm 1.5$ \\
\hline $20(R)-\mathrm{Rg}_{3}$ & i.v. & 5 mg/kg & $46439.2 \pm 14365.5$ & 0.033 & $11919.3 \pm 1896.3$ & $1.5 \pm 0.4$ \\
\hline $20(S)-\mathrm{Rg}_{3}$ & i.g. & $50 \mathrm{mg} / \mathrm{kg}$ & $98.1 \pm 40.5$ & $5.7 \pm 2.0$ & $672.1 \pm 308.1$ & $2.2 \pm 0.4$ \\
\hline
\end{tabular}

Adopted from Peng et al. (2016a).

of $\mathrm{Rg}_{3}$. The structure-activity relationship of $20(\mathrm{~S})-/ 20(\mathrm{R})-\mathrm{Rg}_{3}$ has been investigated on the determination of their difference in NMR spectroscopy and inhibition activities on $\mathrm{Na}^{+}$channel current. The superimposition of 20 structures of $20(\mathrm{~S})$ - and $20(\mathrm{R})-\mathrm{Rg}_{3}$ indicates that the alkene chain of $20(\mathrm{R})-\mathrm{Rg}_{3}$ is more flexible, however, that of $20(\mathrm{~S})-\mathrm{Rg}_{3}$ seems to be stable and tightly packed near the aglycon backbone. Moreover, the space filling representations of these two epimer (Figure 3) showed that the hydroxyl groups of $\mathrm{HO} 12$ and $\mathrm{HO} 20$ in $20(\mathrm{~S})-\mathrm{Rg}_{3}$ are less accessible to water compared with $20(\mathrm{R})-\mathrm{Rg}_{3}$, while those of the latter epimer are found to be exposed to water. Taken together, the alignment of the $20(\mathrm{~S})-\mathrm{Rg}_{3}$ to receptor regions in $\mathrm{Na}^{+}$channels is easier, and the hydrogen bonds occurred in $20(\mathrm{~S})-\mathrm{Rg}_{3}$ and receptor were more stable (Kang et al., 2005).

The interaction of $20(\mathrm{~S})$ and $20(\mathrm{R})-\mathrm{Rg}_{3}$ with human serum albumin (HSA) has been investigated using surface-enhanced Raman scattering (SERS) and fluorescence spectroscopy. Results indicate that HSA is prone to bind to glucose ring upon the interaction with $\mathrm{Rg}_{3}$, with the aglycon part exposed outside. Thus when the combination of $20(\mathrm{~S})$ - or $20(\mathrm{R})-\mathrm{Rg}_{3}-\mathrm{HAS}$ complex with targeting binding site occurs, the stereoscopic spatial structures of these two epimers at C-20 may cause different binding affinities and biological activities (Zhang et al., 2014). Computational modeling has been utilized to elucidate the mechanism of stereospecific activities of $20(\mathrm{~S})-\mathrm{Rg}_{3}$ on peroxisome proliferatoractivated receptor-gamma $(\operatorname{PPAR} \gamma)$. It has been verified that Tyr473 in helix-12 is crucial to full agonistic activity of PPAR $\gamma$. The docking results reveal that the hydroxyl group at C-20 of
$20(\mathrm{~S})-\mathrm{Rg}_{3}$ interacts with Tyr473 via hydrogen bond. However, $20(\mathrm{R})-\mathrm{Rg}_{3}$ is not able to interact with Tyr473 optimally due to its sterically strained binding pocket (Figure 4). It can be inferred that the biological activities difference of $20(\mathrm{~S})$ - and $20(\mathrm{R})-\mathrm{Rg}_{3}$ on PPAR $\gamma$ is due to their different binding affinities according to stereo-structures (Kwok et al., 2012).

\section{PHARMACOKINETICS}

Saponin stereoisomers are proved to exhibit different pharmacokinetic characteristics including absorption, distribution, and metabolism. Bae et al. (2013) developed a LC-MS/MS method for simultaneous determination of $\mathrm{Rg}_{3}$ and $\mathrm{Rh}_{2}$ epimers, and the method was successfully applied to a pharmacokinetic study after oral administration of fermented ginseng extract in rats. 20(S)-epimers of both $\mathrm{Rg}_{3}$ and $\mathrm{Rh}_{2}$ showed significantly higher plasma concentrations and area under curve (AUC) values compared with their corresponding 20(R)-epimers. It can be inferred that 20(R)-epimers of $\mathrm{Rg}_{3}$ and $\mathrm{Rh}_{2}$ have lower membrane permeability and poorer absorption. Moreover, the absorption profiles of $20(\mathrm{~S})-\mathrm{Rh}_{2}$ was proved to be better than those of $20(\mathrm{R})-\mathrm{Rh}_{2}$, partly because $20(\mathrm{R})$ $\mathrm{Rh}_{2}$ performs more potent $\mathrm{ABC}$-transporter-mediated efflux (Gu et al., 2010). Moreover, Bae et al. found that Bacteroides sp., Eubacterium sp., and Bifidobacterium sp. isolated from human fecal microflora can metabolize $\mathrm{Rg}_{3}$ to $\mathrm{PPD}$ via $\mathrm{Rh}_{2}$, however, Fusobacterium sp. is able to metabolize $\mathrm{Rg}_{3}$ to $\mathrm{Rh}_{2}$. The metabolism speed of $20(\mathrm{~S})-\mathrm{Rg}_{3}$ to its 20 (S)-metabolites is 19-time 


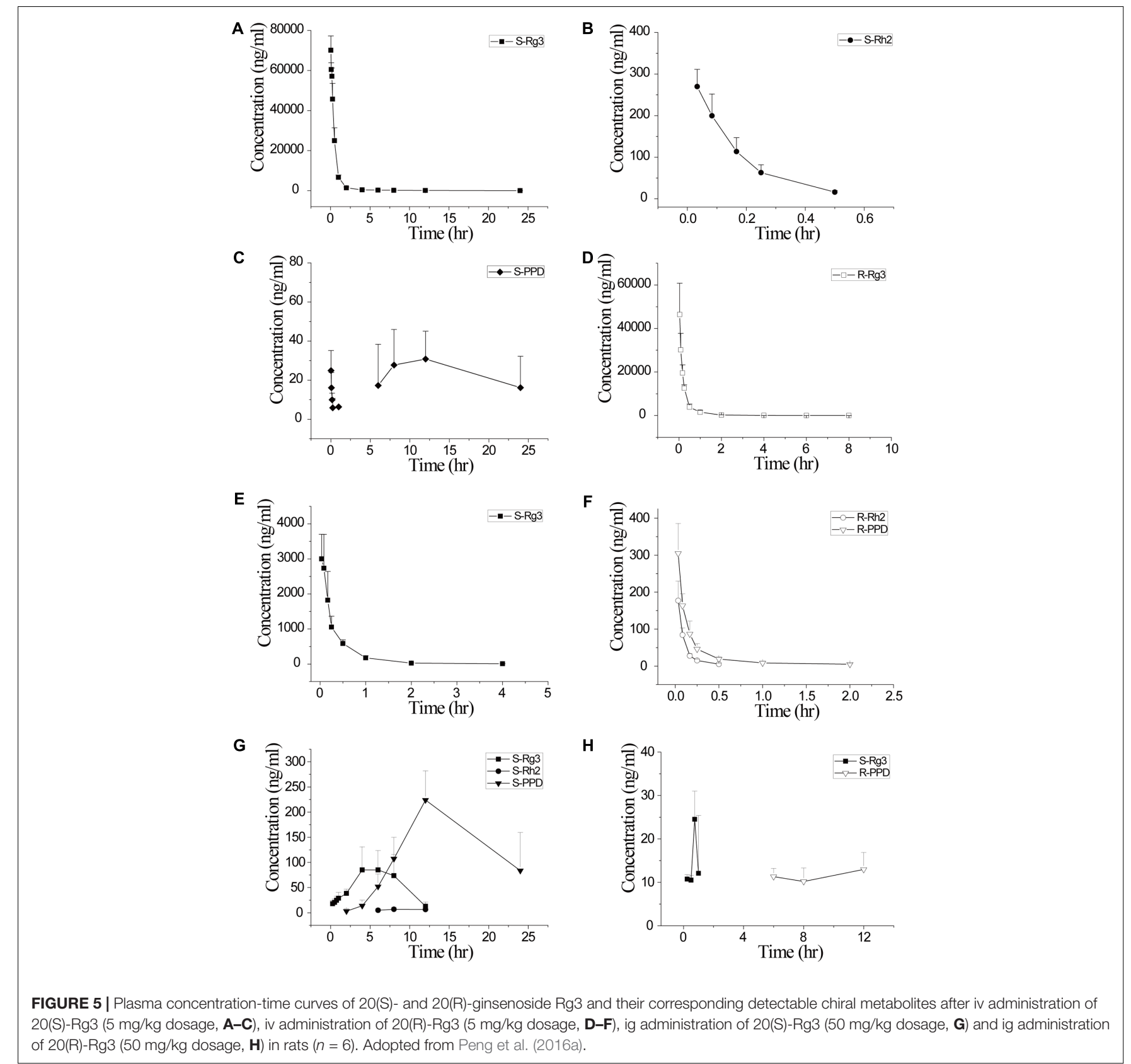

higher than that of $20(\mathrm{R})-\mathrm{Rg}_{3}$ (Bae et al., 2002). Our group has also found that after a same intravenous dosage of $5 \mathrm{mg} / \mathrm{kg}$ in rats, the AUC of $20(\mathrm{~S})-\mathrm{Rg}_{3}$ was about 2.3 times greater than that of $20(\mathrm{R})-\mathrm{Rg}_{3}$. The half time of $20(\mathrm{~S})-\mathrm{Rg}_{3}$ was much longer and the clearance was lower (Table 6). A single direction chiral inversion of $20(\mathrm{R})-\mathrm{Rg}_{3}$ to 20 (S) $-\mathrm{Rg}_{3}$ was found in rats both after intravenous and intra-gastric administration. Both $\mathrm{Rg}_{3}$ epimers can undergo deglycosylated steps to their corresponding C20 chiral configurations of $\mathrm{Rh}_{2}$ and PPD, but the deglycosylation rates and patterns were different (Figure 5) (Peng et al., 2016a). The pharmacokinetic studies of stereospecific properties of ginsenoside stereoisomers may provide an experimental basis to explain the different activities of two stereoisomers.

\section{DISCUSSIONS AND OUTLOOK}

Panax notoginseng is a traditional Chinese medical drug rich in dammarane-type tetracyclic triterpenoid saponins. Some naturally existed major saponins will be deglycosylated or dehydrated to become secondary saponins during the heating processing of $P$. notoginseng. Researches on the chemical components of raw and processed notoginseng indicate that the transformation of compound basis is the basic reason for the changes in their pharmacological effects. A majority of these secondary saponins are stereoisomeric saponins which have been tentatively assigned to be "biomarkers" in processed notoginseng. Available investigations reveal that a diversity of 
distinctly different pharmacological activities, pharmacokinetic behaviors exhibits between two saponin stereoisomers.

The phenomenon of stereoisomerism has gained great attention on chemical drugs by many pharmaceutical enterprises. A very famous example is the disaster caused by thalidomide in 1960s in pharmaceutical history. 8000-12000 infants were born to be limb malformed owing to the exposure to this drug during the pregnancy period of their mothers (Melchert and List, 2007). The reason is that the structure of thalidomide is racemic, with $\mathrm{R}-(+)$ conformation exhibiting high antiepileptic effect, while $\mathrm{S}-(-)$ conformation presenting strong teratogenic effect. However, the pharmacological difference in these two epimers has not been recognized at that time. Lessons have been learned from this tragedy that the separation and the study of drug stereoisomers are of great importance. With the development of the research on stereoisomeric drugs in recent years, the best four selling drug on the list of top ten global ranking list in 2006 were chiral drugs which were optically pure. However, stereoisomerism of natural compounds has not been studied extensively. Although stereoisomeric saponins have already attracted the interest of researchers, the investigations on the pharmacological differences have only been focused on ginsenoside $\mathrm{Rg}_{3}$ and $\mathrm{Rh}_{2}$, which are far below enough. More studies on pharmacological activities of minor saponin isomers produced in processed notoginseng, biological difference and pharmacokinetic behaviors in stereoisomeric saponins and the underlying mechanisms, and the preparation methods of stereoisomeric saponins need to be performed. Moreover, other cost-effective, efficient, and environmentally friendly

\section{REFERENCES}

Bae, E.-A., Han, M. J., Choo, M.-K., Park, S.-Y., and Kim, D.-H. (2002). Metabolism of 20(S)- and 20(R)-ginsenoside Rg3 by human intestinal bacteria and its relation to in vitro biological activities. Biol. Pharm. Bull. 25, 58-63. doi: 10.1248/bpb.25.58

Bae, S. H., Zheng, Y. F., Yoo, Y. H., Kim, J. Y., Kim, S. O., Jang, M. J., et al. (2013). Stereoselective determination of ginsenosides Rg3 and Rh2 epimers in rat plasma by LC-MS/MS: application to a pharmacokinetic study. J. Sep. Sci. 36, 1904-1912. doi: 10.1002/jssc.201300107

Chan, E. C., Yap, S. L., Lau, A. J., Leow, P. C., Toh, D. F., and Koh, H. L. (2007). Ultra-performance liquid chromatography/time-of-flight mass spectrometry based metabolomics of raw and steamed Panax notoginseng. Rapid Commun. Mass Spectrom. 21, 519-528. doi: 10.1002/rcm.2864

Chen, B., Li, X.-D., Liu, D.-X., Wang, H., Xie, P., Liu, Z.-Y., et al. (2012). Canonical Wnt signaling is required for Panax notoginseng saponin-mediated attenuation of the RANKL/OPG ratio in bone marrow stromal cells during osteogenic differentiation. Phytomedicine 19, 1029-1034. doi: 10.1016/j.phymed.2012. 06.002

Cheng, L.-Q., Na, J. R., Bang, M. H., Kim, M. K., and Yang, D.-C. (2008). Conversion of major ginsenoside Rb1 to 20(S)-ginsenoside Rg3 by Microbacterium sp. GS514. Phytochemistry 69, 218-224. doi: 10.1016/j. phytochem.2007.06.035

Choi, S.-H., Shin, T.-J., Hwang, S.-H., Lee, B.-H., Kang, J., Kim, H.-J., et al. (2011). Differential effects of ginsenoside metabolites on HERG $\mathrm{K}^{+}$channel currents. J. Ginseng Res. 35, 191-199. doi: 10.5142/jgr.2011.35.2.191

Choi, W.-Y., Lim, H.-W., and Lim, C.-J. (2013). Anti-inflammatory, antioxidative and matrix metalloproteinase inhibitory properties of 20(R)-ginsenoside Rh2 in cultured macrophages and keratinocytes. J. Pharm. Pharmacol. 65, 310-316. doi: 10.1111/j.2042-7158.2012.01598.x microorganic and enzymatic hydrolysis methods for the preparation of optically pure saponins are worthy of further development and exploration. We believe that those researches on stereoisomeric saponins will be beneficial to structure-activity relationship, structure modification and new drug development in phytochemicals.

\section{AUTHOR CONTRIBUTIONS}

$\mathrm{TZ}$ and YD formulated the study concept and design of the paper. MP prepared the Tables 2-6. MP and YY acquired the data, draw the Figure 1 and Table 1, and drafted the manuscript. JL guided the critical revision of the manuscript and provided important intellectual content. All authors reviewed the manuscript, agreed to all the contents, and agreed the submission.

\section{FUNDING}

This work was supported by the Programs of the National Natural Science Foundation of China (Grant Nos. 81403175 and 81274200); Project of the Shanghai Committee of Science and Technology (Grant No. 13401900301); Youth Talent Sail Plan from Shanghai Committee of Science and Technology (Grant No. 14YF1411300); Project of the Shanghai Municipal Health and Family Planning Commission (Grant Nos. 20134Y053, 2017YQ072, and 201740152); Research Fund for the Doctoral Program of Shanghai (Grant No. B201703); and Xinglin Scholar Plan.

Cui, C.-H., Kim, S.-C., and Im, W.-T. (2013a). Characterization of the ginsenosidetransforming recombinant $\beta$-glucosidase from Actinosynnema mirum and bioconversion of major ginsenosides into minor ginsenosides. Appl. Microbiol. Biotechnol. 97, 649-659. doi: 10.1007/s00253-012-4324-5

Cui, C.-H., Liu, Q.-M., Kim, J.-K., Sung, B.-H., Kim, S.-G., Kim, S.-C., et al. (2013b). Identification and characterization of a Mucilaginibacter sp. strain QM49 $\beta$-Glucosidase and its use in the production of the pharmaceutically active minor ginsenosides (S)- $\mathrm{Rh}_{1}$ and (S)-Rg . Appl. Environ. Microbiol. 79, 5788-5798. doi: 10.1128/AEM.01150-13

Cui, L., Wu, S.-Q., Zhao, C.-A., and Yin, C.-R. (2016). Microbial conversion of major ginsenosides in ginseng total saponins by Platycodon grandiflorum endophytes. J. Ginseng Res. 40, 366-374. doi: 10.1016/j.jgr.2015.11.004

Dan, M., Su, M., Gao, X., Zhao, T., Zhao, A., Xie, G., et al. (2008). Metabolite profiling of Panax notoginseng using UPLC-ESI-MS. Phytochemistry 69, 2237-2244. doi: 10.1016/j.phytochem.2008.04.015

Dong, H., Bai, L.-P., Wong, V. K. W., Zhou, H., Wang, J.-R., Liu, Y., et al. (2011). The in vitro structure-related anti-cancer activity of ginsenosides and their derivatives. Molecules 16, 10619-10630. doi: 10.3390/molecules161210619

Du, J., Cui, C.-H., Park, S. C., Kim, J.-K., Yu, H.-S., Jin, F.-X., et al. (2014). Identification and characterization of a ginsenoside-transforming $\beta$-glucosidase from Pseudonocardia sp. Gsoil 1536 and its application for enhanced production of minor ginsenoside $\operatorname{Rg}_{2}(\mathrm{~S})$. PLoS One 9:e96914. doi: 10.1371/ journal.pone.0096914

Fatmawati, S., Ersam, T., Yu, H., Zhang, C., Jin, F., and Shimizu, K. (2014). 20(S)Ginsenoside Rh2 as aldose reductase inhibitor from Panax ginseng. Bioorg. Med. Chem. Lett. 24, 4407-4409. doi: 10.1016/j.bmcl.2014.08.009

Gu, Y., Wang, G. J., Wu, X. L., Zheng, Y. T., Zhang, J. W., Ai, H., et al. (2010). Intestinal absorption mechanisms of ginsenoside $\mathrm{Rh} 2$ : stereoselectivity and involvement of ABC transporters. Xenobiotica 40, 602-612. doi: 10.3109/ 00498254.2010 .500744 
Guo, J. Q., Zheng, Q. H., Chen, H., Chen, L., Xu, J. B., Chen, M. Y., et al. (2014). Ginsenoside Rg3 inhibition of vasculogenic mimicry in pancreatic cancer through downregulation of VEcadherin/EphA2/MMP9/MMP2 expression. Int. J. Oncol. 45, 1065-1072. doi: 10.3892/ijo.2014.2500

Han, S.-Y., Li, H.-X., Ma, X., Zhang, K., Ma, Z.-Z., Jiang, Y., et al. (2013). Evaluation of the anti-myocardial ischemia effect of individual and combined extracts of Panax notoginseng and Carthamus tinctorius in rats. J. Ethnopharmacol. 145, 722-727. doi: 10.1016/j.jep.2012.11.036

Huang, L.-F., Shi, H.-L., Gao, B., Wu, H., Yang, L., Wu, X.-J., et al. (2014). Decichine enhances hemostasis of activated platelets via AMPA receptors. Thromb. Res. 133, 848-854. doi: 10.1016/j.thromres.2014.02.009

Jia, D., Deng, Y., Gao, J., Liu, X., Chu, J., and Shu, Y. (2014). Neuroprotective effect of Panax notoginseng plysaccharides against focal cerebral ischemia reperfusion injury in rats. Int. J. Biol. Macromol. 63, 177-180. doi: 10.1016/j.ijbiomac.2013. 10.034

Jin, X. F., Yu, H. S., Wang, D. M., Liu, T. Q., Liu, C. Y., An, D. S., et al. (2012). Kinetics of a cloned special ginsenosidase hydrolyzing 3-O-glucoside of multiprotopanaxadiol-type ginsenosides, named ginsenosidase type III. J. Microbiol. Biotechnol. 22, 343-351. doi: 10.4014/jmb.1107.07066

Ju, H. K., Lee, J. G., Park, M. K., Park, S. J., Lee, C. H., Park, J. H., et al. (2012). Metabolomic investigation of the anti-platelet aggregation activity of ginsenoside $\mathrm{Rk}(1)$ reveals attenuated 12-HETE production. J. Proteome Res. 11, 4939-4946. doi: 10.1021/pr300454f

Kang, D.-I., Lee, J.-Y., Yang, J.-Y., Jeong, S. M., Lee, J.-H., Nah, S.-Y., et al. (2005). Evidence that the tertiary structure of $20(S)$-ginsenoside $\mathrm{Rg}_{3}$ with tight hydrophobic packing near the chiral center is important for $\mathrm{Na}^{+}$channel regulation. Biochem. Biophys. Res. Commun. 333, 1194-1201. doi: 10.1016/j. bbrc.2005.06.026

Kang, M. S., Baek, S.-H., Chun, Y. S., Moore, A. Z., Landman, N., Berman, D., et al. (2013). Modulation of lipid kinase PI4KII $\alpha$ activity and lipid raft association of presenilin 1 underlies $\gamma$-secretase inhibition by ginsenoside (20S)-Rg3. J. Biol. Chem. 288, 20868-20882. doi: 10.1074/jbc.M112.445734

Kim, B.-M., Kim, D.-H., Park, J.-H., Surh, Y.-J., and Na, H.-K. (2014). Ginsenoside $\mathrm{Rg} 3$ inhibits constitutive activation of NF- $\mathrm{BB}$ signaling in human breast cancer (MDA-MB-231) cells: ERK and Akt as potential upstream targets. J. Cancer Prev. 19, 23-30. doi: 10.15430/JCP.2014.19.1.23

Kim, E.-J., Jung, I.-H., Van Le, T. K., Jeong, J.-J., Kim, N.-J., and Kim, D.-H. (2013). Ginsenosides Rg5 and Rh3 protect scopolamine-induced memory deficits in mice. J. Ethnopharmacol. 146, 294-299. doi: 10.1016/j.jep.2012.12.047

Kim, J.-H., Lee, J.-H., Jeong, S. M., Lee, B.-H., Yoon, I.-S., Lee, J.-H., et al. (2006). Stereospecific effects of ginsenoside $\mathrm{Rg}_{3}$ epimers on swine coronary artery contractions. Biol. Pharm. Bull. 29, 365-370. doi: 10.1248/bpb.29.365

Kim, J.-K., Cui, C.-H., Yoon, M.-H., Kim, S.-C., and Im, W.-T. (2012). Bioconversion of major ginsenosides $\mathrm{Rg}_{1}$ to minor ginsenoside $\mathrm{F}_{1}$ using novel recombinant ginsenoside hydrolyzing glycosidase cloned from Sanguibacter keddieii and enzyme characterization. J. Biotechnol. 161, 294-301. doi: 10.1016/ j.jbiotec.2012.06.021

Kim, J. S., Joo, E. J., Chun, J., Ha, Y. W., Lee, J.-H., Han, Y., et al. (2012). Induction of apoptosis by ginsenoside Rk1 in SK-MEL-2-human melanoma. Arch. Pharm. Res. 35, 717-722. doi: 10.1007/s12272-012-0416-0

Kim, S. S., Jang, H. J., Oh, M. Y., Eom, D. W., Kang, K. S., Kim, Y. J., et al. (2014). Ginsenoside Rg3 enhances islet cell function and attenuates apoptosis in mouse islets. Transplant. Proc. 46, 1150-1155. doi: 10.1016/j.transproceed.2013.12.028

Kim, Y.-J., Choi, W.-I., Jeon, B.-N., Choi, K.-C., Kim, K., Kim, T.-J., et al. (2014). Stereospecific effects of ginsenoside $20-\operatorname{Rg} 3$ inhibits TGF- $\beta 1$-induced epithelial-mesenchymal transition and suppresses lung cancer migration, invasion and anoikis resistance. Toxicology 322, 23-33. doi: 10.1016/j.tox.2014. 04.002

Kim, Y. J., Yamabe, N., Choi, P., Lee, J. W., Ham, J., and Kang, K. S. (2013). Efficient thermal deglycosylation of ginsenoside Rd and its contribution to the improved anticancer activity of ginseng. J. Agric. Food Chem. 61, 9185-9191. doi10.1021/jf402774d doi: 10.1021/jf402774d

Krizevski, R., Bar, E., Shalit, O., Sitrit, Y., Ben-Shabat, S., and Lewinsohn, E. (2010). Composition and stereochemistry of ephedrine alkaloids accumulation in Ephedra sinica Stapf. Phytochemistry 71, 895-903. doi: 10.1016/j.phytochem. 2010.03.019

Kudo, K., Tachikawa, E., Kashimoto, T., and Takahashi, E. (1998). Properties of ginseng saponin inhibition of catecholamine secretion in bovine adrenal chromaffin cells. Eur. J. Pharmacol. 341, 139-144. doi: 10.1016/S0014-2999(97) 01350-2

Kwok, H.-H., Guo, G.-L., Lau, J. K.-C., Cheng, Y.-K., Wang, J.-R., Jiang, Z.-H., et al. (2012). Stereoisomers ginsenosides-20(S)-Rg3 and -20(R)-Rg3 differentially induce angiogenesis through peroxisome proliferator-activated receptor-gamma. Biochem. Pharmacol. 83, 893-902. doi: 10.1016/j.bcp.2011. 12.039

Lau, A. J., Seo, B. H., Woo, S. O., and Koh, H. L. (2004). High-performance liquid chromatographic method with quantitative comparisons of whole chromatograms of raw and steamed Panax notoginseng. J. Chromatogr. A 1057, 141-149. doi: 10.1016/j.chroma.2004.09.069

Lau, A.-J., Toh, D.-F., Chua, T.-K., Pang, Y.-K., Woo, S.-O., and Koh, H.-L. (2009). Antiplatelet and anticoagulant effects of Panax notoginseng: Comparison of raw and steamed Panax notoginseng with Panax ginseng and Panax quinquefolium. J. Ethnopharmacol. 125, 380-386. doi: 10.1016/j.jep.2009.07.038

Lau, A. J., Woo, S. O., and Koh, H. L. (2003). Analysis of saponins in raw and steamed Panax notoginseng using high-performance liquid chromatography with diode array detection. J. Chromatogr. A 1011, 77-87. doi: 10.1016/S00219673(03)01135-X

Lee, B., Sur, B., Park, J., Kim, S.-H., Kwon, S., Yeom, M., et al. (2013). Ginsenoside $\mathrm{Rg} 3$ alleviates lipopolysaccharide-induced learning and memory impairments by anti-inflammatory activity in rats. Biomol. Ther. 21, 381-390. doi: 10.4062/ biomolther.2013.053

Lee, B.-H., Lee, J.-H., Yoon, I.-S., Lee, J.-H., Choi, S.-H., Shin, T.-J., et al. (2007). Mutations of arginine 222 in pre-transmembrane domain I of mouse $5-\mathrm{HT}_{3 \mathrm{~A}}$ receptor abolish $20(R)$ - but not $20(S)$-ginsenoside $\mathrm{Rg}_{3}$ inhibition of 5-HTmediated ion currents. Biol. Pharm. Bull. 30, 1721-1726. doi: 10.1248/bpb. 30.1721

Lee, J. G., Lee, Y. Y., Kim, S. Y., Pyo, J. S., Yun-Choi, H. S., and Park, J. H. (2009). Platelet antiaggregating activity of ginsenosides isolated from processed ginseng. Pharmazie 64, 602-604.

Lee, J. Y., Jung, K. H., Morgan, M. J., Kang, Y. R., Lee, H. S., Koo, G. B., et al. (2013). Sensitization of TRAIL-induced cell death by $20(\mathrm{~S})$-ginsenoside $\mathrm{Rg}_{3}$ via CHOP-mediated DR5 upregulation in human hepatocellular carcinoma cells. Mol. Cancer Ther. 12, 274-285. doi: 10.1158/1535-7163.MCT-12-0054

Lee, Y. Y., Park, J.-S., Jung, J.-S., Kim, D.-H., and Kim, H.-S. (2013). Antiinflammatory effect of ginsenoside $\mathrm{Rg} 5$ in lipopolysaccharide-stimulated BV2 microglial cells. Int. J. Mol. Sci. 14, 9820-9833. doi: 10.3390/ijms140 59820

Liao, P. Y., Wang, D., Zhang, Y. J., and Yang, C. R. (2008). Dammarane-type glycosides from steamed notoginseng. J. Agric. Food Chem. 56, 1751-1756. doi: $10.1021 /$ jf073000s

Lim, C.-J., Choi, W.-Y., and Jung, H.-J. (2014). Stereoselective skin anti-photoaging properties of ginsenoside Rg3 in UV-B-irradiated keratinocytes. Biol. Pharm. Bull. 37, 1583-1590. doi: 10.1248/bpb.b14-00167

Liu, G., Wang, B., Zhang, J., Jiang, H., and Liu, F. (2009). Total panax notoginsenosides prevent atherosclerosis in apolipoprotein E-knockout mice: role of downregulation of CD40 and MMP-9 expression. J. Ethnopharmacol. 126, 350-354. doi: 10.1016/j.jep.2009.08.014

Liu, J., Shimizu, K., Yu, H., Zhang, C., Jin, F., and Kondo, R. (2010a). Stereospecificity of hydroxyl group at C-20 in antiproliferative action of ginsenoside Rh2 on prostate cancer cells. Fitoterapia 81, 902-905. doi: 10.1016/ j.fitote.2010.05.020

Liu, J., Shiono, J., Shimizu, K., Yu, H., Zhang, C., Jin, F., et al. (2009). 20(R)Ginsenoside Rh2, not 20(S), is a selective osteoclastgenesis inhibitor without any cytotoxicity. Bioorg. Med. Chem. Lett. 19, 3320-3323. doi: 10.1016/j.bmcl. 2009.04.054

Liu, L., Gu, L.-J., Zhang, D.-L., Wang, Z., Wang, C.-Y., Li, Z., et al. (2010b). Microbial conversion of rare ginsenoside Rf to $20(S)$-protopanaxatriol by Aspergillus niger. Biosci. Biotechnol. Biochem. 74, 96-100. doi: 10.1271/bbb. 90596

Liu, L., Zhu, X.-M., Wang, Q.-J., Zhang, D.-L., Fang, Z.-M., Wang, C.-Y., et al. (2010c). Enzymatic preparation of 20(S, R)-protopanaxadiol by transformation of 20(S, R)-Rg3 from black ginseng. Phytochemistry 71, 1514-1520. doi: 10.1016/j.phytochem.2010.05.007

Luk, K. F., Ko, K. M., and Ng, K. M. (2008). Separation and purification of (-)schisandrin B from schisandrin B stereoisomers. Biochem. Eng. J. 42, 55-60. doi: 10.1016/j.bej.2008.05.018 
Luo, F.-C., Wang, S.-D., Li, K., Nakamura, H., Yodoi, J., and Bai, J. (2010). Panaxatriol saponins extracted from Panax notoginseng induces thioredoxin-1 and prevents 1-methyl-4-phenylpyridinium ion-induced neurotoxicity. J. Ethnopharmacol. 127, 419-423. doi: 10.1016/j.jep.2009.10.023

Maeng, Y.-S., Maharjan, S., Kim, J.-H., Park, J.-H., Suk, Yu, Y., et al. (2013). Rk1, a ginsenoside, is a new blocker of vascular leakage acting through actin structure remodeling. PLoS One 8:e68659. doi: 10.1371/journal.pone.0068659

Medicine SAoTC (1996). Chinese Materia Medica Featured. Beijing: Shanghai Science and Technology Press.

Melchert, M., and List, A. (2007). The thalidomide saga. Int. J. Biochem. Cell Biol. 39, 1489-1499. doi: 10.1016/j.biocel.2007.01.022

Min, J.-K., Kim, J.-H., Cho, Y.-L., Maeng, Y.-S., Lee, S.-J., Pyun, B.-J., et al. (2006). 20(S)-Ginsenoside Rg3 prevents endothelial cell apoptosis via inhibition of a mitochondrial caspase pathway. Biochem. Biophys. Res. Commun. 349, 987-994. doi: 10.1016/j.bbrc.2006.08.129

Nagai, T., Shimizu, Y., Shirahata, T., Sunazuka, T., Kiyohara, H., Ômura, S., et al. (2010). Oral adjuvant activity for nasal influenza vaccines caused by combination of two trihydroxy fatty acid stereoisomers from the tuber of Pinellia ternata. Int. Immunopharmacol. 10, 655-661. doi: 10.1016/j.intimp. 2010.03.004

Nose, M., Ito, M., Kamimura, K., Shimizu, M., and Ogihara, Y. (1994). A comparison of the antihepatotoxic activity between glycyrrhizin and glycyrrhetinic acid. Planta Med. 60, 136-139. doi: 10.1055/s-2006959435

Oh, S.-J., Lee, S., Choi, W. Y., and Lim, C. J. (2014). Skin anti-photoaging properties of ginsenoside Rh2 epimers in UV-B-irradiated human keratinocyte cells. J. Biosci. 39, 637-682. doi: 10.1007/s12038-014-9460-x

Pan, C., Huo, Y., An, X., Singh, G., Chen, M., Yang, Z., et al. (2012). Panax notoginseng and its components decreased hypertension via stimulation of endothelial-dependent vessel dilatation. Vasc. Pharmacol. 56, 150-158. doi: 10. 1016/j.vph.2011.12.006

Park, E.-H., Kim, Y.-J., Yamabe, N., Park, S.-H., Kim, H.-K., Jang, H.-J., et al. (2014). Stereospecific anticancer effects of ginsenoside Rg3 epimers isolated from heatprocessed American ginseng on human gastric cancer cell. J. Ginseng Res. 38, 22-27. doi: 10.1016/j.jgr.2013.11.007

Park, H.-W., In, G., Han, S.-T., Lee, M.-W., Kim, S.-Y., Kim, K.-T., et al. (2013). Simultaneous determination of 30 ginsenosides in Panax ginseng preparations using ultra performance liquid chromatography. J. Ginseng Res. 37, 457-467. doi: 10.5142/jgr.2013.37.457

Park, J. H. (2004). Sun ginseng-A new processed ginseng with fortified activity. Food. Ind. Nutr. 9, 23-27.

Park, J. Y., Choi, P., Lee, D., Kim, T., Jung, E. B., Hwang, B.-S., et al. (2016). Effect of amino acids on the generation of ginsenoside $\mathrm{Rg} 3$ epimers by heat processing and the anticancer activities of epimers in A2780 human ovarian cancer cells. Evid. Based Complement. Alternat. Med. 2016:3146402. doi: 10. 1155/2016/3146402

Park, M. W., Ha, J., and Chung, S. H. (2008). 20(S)-ginsenoside Rg3 enhances glucose-stimulated insulin secretion and activates AMPK. Biol. Pharm. Bull. 31, 748-751. doi: 10.1248/bpb.31.748

Park, S.-M., Choi, M.-S., Sohn, N.-W., and Shin, J.-W. (2012). Ginsenoside Rg3 attenuates microglia activation following systemic lipopolysaccharide treatment in mice. Biol. Pharm. Bull. 35, 1546-1552. doi: 10.1248/bpb.b12-00393

Peng, M., Li, X., Zhang, T., Ding, Y., Yi, Y., Le, J., et al. (2016a). Stereoselective pharmacokinetic and metabolism studies of 20(S)- and 20(R)-ginsenoside $\mathrm{Rg}_{3}$ epimers in rat plasma by liquid chromatography-electrospray ionization mass spectrometry. J. Pharm. Biomed. Anal. 121, 215-224. doi: 10.1016/j.jpba.2016. 01.020

Peng, M., Zhang, T., Ding, Y., Yi, Y., Yang, Y., and Le, J. (2016b). Structurebased prediction of CAD response factors of dammarane-type tetracyclic triterpenoid saponins and its application to the analysis of saponin contents in raw and processed Panax Notoginseng. RSC Adv. 6, 36987-37005. doi: 10.1039/ c6ra03193e

Qi, L.-W., Wang, H.-Y., Zhang, H., Wang, C.-Z., Li, P., and Yuan, C.-S. (2012). Diagnostic ion filtering to characterize ginseng saponins by rapid liquid chromatography with time-of-flight mass spectrometry. J. Chromatogr. A 1230, 93-99. doi: 10.1016/j.chroma.2012.01.079

Qiu, X.-M., Bai, X., Jiang, H.-F., He, P., and Wang, J.-H. (2014). 20-(s)-Ginsenoside $\mathrm{Rg} 3$ induces apoptotic cell death in human leukemic U937 and HL-60 cells through PI3K/Akt pathways. Anticancer Drugs 25, 1072-1080. doi: 10.1097/ CAD.0000000000000147

Quan, L.-H., Min, J.-W., Yang, D.-U., Kim, Y.-J., and Yang, D.-C. (2012). Enzymatic biotransformation of ginsenoside $\mathrm{Rb} 1$ to $20(S)-\mathrm{Rg} 3$ by recombinant $\beta$-glucosidase from Microbacterium esteraromaticum. Appl. Microbiol. Biotechnol. 94, 377-384. doi: 10.1007/s00253-011-3861-7

Ren, D.-M., Guo, H.-F., Wang, S.-Q., and Lou, H.-X. (2007). Separation and structure determination of two diastereomeric pairs of enantiomers from Dracocephalum rupestre by high-performance liquid chromatography with circular dichroism detection. J. Chromatogr. A 1161, 334-337. doi: 10.1016/j. chroma.2007.06.034

Rhule, A., Rase, B., Smith, J. R., and Shepherd, D. M. (2008). Toll-like receptor ligand-induced activation of murine DC2.4 cells is attenuated by Panax notoginseng. J. Ethnopharmacol. 116, 179-186. doi: 10.1016/j.jep.2007. 11.019

Sakah, K. J., Wang, T., Liu, L., Chen, Y., Han, L., and Zhang, Y. (2013). Eight darmarane-type saponins isolated from the roots of Panax notoginseng. Acta Pharm. Sin. B 3, 381-384. doi: 10.1016/j.apsb.2013.09.004

Shan, X., Tian, L. L., Zhang, Y. M., Wang, X. Q., Yan, Q., and Liu, J. W. (2015). Ginsenoside Rg3 suppresses FUT4 expression through inhibiting NFkappaB/p65 signaling pathway to promote melanoma cell death. Int. J. Oncol. 47, 701-709. doi: 10.3892/ijo.2015.3057

Shi, X., Yu, W., Yang, T., Liu, W., Zhao, Y., Sun, Y., et al. (2016). Panax notoginseng saponins provide neuroprotection by regulating NgR1/RhoA/ROCK2 pathway expression, in vitro and in vivo. J. Ethnopharmacol. 190, 301-312. doi: 10.1016/ j.jep.2016.06.017

Song, Y., Hou, J., Kang, L., and Gao, S. (2014a). Effect of 20 (S)-ginsenoside Rg3 on the proliferation inhibition and secretion of vascular endothelial growth factor of multiple myeloma cell line U266. Zhonghua Xue Ye Xue Za Zhi 35, 519-523. doi: 10.3760/cma.j.issn.0253-2727.2014.06.010

Song, Y., Jing, W., Yang, F., Shi, Z., Yao, M., Yan, R., et al. (2014b). Simultaneously enantiospecific determination of $(+)$-trans-khellactone, $(+/-)$-praeruptorin $\mathrm{A},(+/-)$-praeruptorin $\mathrm{B},(+)$-praeruptorin $\mathrm{E}$, and their metabolites, $(+/-)$ cis-khellactone, in rat plasma using online solid phase extraction-chiral LCMS/MS. J. Pharm. Biomed. Anal. 88, 269-277. doi: 10.1016/j.jpba.2013.08. 042

Sun, B.-S., Gu, L.-J., Fang, Z.-M., Wang, C.-Y., Wang, Z., Lee, M.-R., et al. (2009). Simultaneous quantification of 19 ginsenosides in black ginseng developed from Panax ginseng by HPLC-ELSD. J. Pharm. Biomed. Anal. 50, 15-22. doi: 10.1016/j.jpba.2009.03.025

Sun, C., Yu, Y., Wang, L., Wu, B., Xia, L., Feng, F., et al. (2016). Additive antiangiogenesis effect of ginsenoside $\mathrm{Rg} 3$ with low-dose metronomic temozolomide on rat glioma cells both in vivo and in vitro. J. Exp. Clin. Cancer Res. 35:32. doi: 10.1186/s13046-015-0274-y

Sun, H., Yang, Z., and Ye, Y. (2006). Structure and biological activity of protopanaxatriol-type saponins from the roots of Panax notoginseng. Int. Immunopharmacol. 6, 14-25. doi: 10.1016/j.intimp.2005.07.003

Sun, J., Sun, G., Meng, X., Wang, H., Wang, M., Qin, M., et al. (2013). Ginsenoside RK3 prevents hypoxia-reoxygenation induced apoptosis in H9c2 cardiomyocytes via AKT and MAPK pathway. Evid. Based Complement. Alternat. Med. 2013:690190. doi: 10.1155/2013/690190

Sun, S., Qi, L.-W., Du, G.-J., Mehendale, S. R., Wang, C.-Z., and Yuan, C.-S. (2011). Red notoginseng: higher ginsenoside content and stronger anticancer potential than Asian and American ginseng. Food Chem. 125, 1299-1305. doi: 10.1016/j.foodchem.2010.10.049

Sun, S., Wang, C.-Z., Tong, R., Li, X.-L., Fishbein, A., Wang, Q., et al. (2010). Effects of steaming the root of Panax notoginseng on chemical composition and anticancer activities. Food Chem. 118, 307-314. doi: 10.1016/j.foodchem.2009. 04.122

Toh, D.-F., New, L.-S., Koh, H.-L., and Chan, E. C.-Y. (2010). Ultrahigh performance liquid chromatography/time-of-flight mass spectrometry (UHPLC/TOFMS) for time-dependent profiling of raw and steamed Panax notoginseng. J. Pharm. Biomed. Anal. 52, 43-50. doi: 10.1016/j.jpba.2009. 12.005

Toh, D.-F., Patel, D. N., Chan, E. C.-Y., Teo, A., Neo, S.-Y., and Koh, H.-L. (2011). Anti-proliferative effects of raw and steamed extracts of Panax notoginseng and its ginsenoside constituents on human liver cancer cells. Chin. Med. 6:4. doi: $10.1186 / 1749-8546-6-4$ 
Wan, J. B., Li, S. P., Chen, J. M., and Wang, Y. T. (2007). Chemical characteristics of three medicinal plants of the Panax genus determined by HPLC-ELSD. J. Sep. Sci. 30, 825-832. doi: 10.1002/jssc.200600359

Wan, J.-B., Zhang, Q.-W., Hong, S.-J., Li, P., Li, S.-P., and Wang, Y.-T. (2012). Chemical investigation of saponins in different parts of Panax notoginseng by pressurized liquid extraction and liquid chromatography-electrospray ionization-tandem mass spectrometry. Molecules 17, 5836-5853. doi: 10.3390/ molecules 17055836

Wan, J.-Y., Liu, P., Wang, H.-Y., Qi, L.-W., Wang, C.-Z., Li, P., et al. (2013). Biotransformation and metabolic profile of American ginseng saponins with human intestinal microflora by liquid chromatography quadrupole time-offlight mass spectrometry. J. Chromatogr. A 1286, 83-92. doi: 10.1016/j.chroma. 2013.02.053

Wang, C.-Z., McEntee, E., Wicks, S., Wu, J.-A., and Yuan, C.-S. (2006). Phytochemical and analytical studies of Panax notoginseng (Burk.) F.H. Chen. J. Nat. Med. 60, 97-106. doi: 10.1007/s11418-005-0027-x

Wang, D., Liao, P.-Y., Zhu, H.-T., Chen, K.-K., Xu, M., Zhang, Y.-J., et al. (2012). The processing of Panax notoginseng and the transformation of its saponin components. Food Chem. 132, 1808-1813. doi: 10.1016/j.foodchem.2011. 12.010

Wang, D. M., Yu, H. S., Song, J. G., Xu, Y. F., Liu, C. Y., and Jin, F. X. (2011). A novel ginsenosidase from an Aspergillus strain hydrolyzing 6-O-multi-glycosides of protopanaxatriol-type ginsenosides, named ginsenosidase type IV. J. Microbiol. Biotechnol. 21, 1057-1063. doi: 10.4014/jmb.1101.01044

Wang, J.-H., Nao, J.-F., Zhang, M., and He, P. (2014). 20(s)-ginsenoside Rg3 promotes apoptosis in human ovarian cancer HO-8910 cells through PI3K/Akt and XIAP pathways. Tumor Biol. 35, 11985-11994. doi: 10.1007/s13277-0142497-5

Wang, M., Zhang, X.-J., Liu, F., Hu, Y., He, C., Li, P., et al. (2015). Saponins isolated from the leaves of Panax notoginseng protect against alcoholic liver injury via inhibiting ethanol-induced oxidative stress and gut-derived endotoxinmediated inflammation. J. Funct. Foods 19, 214-224. doi: 10.1016/j.jff.2015.09. 029

Wang, T., Guo, R., Zhou, G., Zhou, X., Kou, Z., Sui, F., et al. (2016). Traditional uses, botany, phytochemistry, pharmacology and toxicology of Panax notoginseng (Burk.) F.H. Chen: a review. J. Ethnopharmacol. 188, 234-258. doi: 10.1016/j.jep.2016.05.005

Wang, Y., You, J., Yu, Y., Qu, C., Zhang, H., Ding, L., et al. (2008). Analysis of ginsenosides in Panax ginseng in high pressure microwave-assisted extraction. Food Chem. 110, 161-167. doi: 10.1016/j.foodchem.2008.01.028

Wei, X., Chen, J., Su, F., Su, X., Hu, T., and Hu, S. (2012a). Stereospecificity of ginsenoside $\mathrm{Rg} 3$ in promotion of the immune response to ovalbumin in mice. Int. Immunol. 24, 465-471. doi: 10.1093/intimm/dxs043

Wei, X., Su, F., Su, X., Hu, T., and Hu, S. (2012b). Stereospecific antioxidant effects of ginsenoside $\mathrm{Rg} 3$ on oxidative stress induced by cyclophosphamide in mice. Fitoterapia 83, 636-642. doi: 10.1016/j.fitote.2012.01.006

Wu, L., Zhang, W., Tang, Y.-H., Li, H., Chen, B.-Y., Zhang, G.-M., et al. (2010). Effect of total saponins of "Panax notoginseng root" on aortic intimal hyperplasia and the expressions of cell cycle protein and extracellular matrix in rats. Phytomedicine 17, 233-240. doi: 10.1016/j.phymed.2009. 07.021

Wu, R., Ru, Q., Chen, L., Ma, B., and Li, C. (2014). Stereospecificity of ginsenoside $\mathrm{Rg} 3$ in the promotion of cellular immunity in hepatoma H22-bearing mice. J. Food Sci. 79, H1430-H1435. doi: 10.1111/1750-3841.12518

Xia, J., Chen, D., Zuo, G., Wei, Q., You, Z., Li, D., et al. (2014). Regulatory effect of ginsenoside Rh2 on HDAC1/2 activity and cyclin in human erythroleukemia K562 cells. Chin. J. Cell. Mol. Immunol. 30, 1062-1066.
Xia, W., Sun, C., Zhao, Y., and Wu, L. (2011). Hypolipidemic and antioxidant activities of Sanchi (Radix Notoginseng) in rats fed with a high fat diet. Phytomedicine 18, 516-520. doi: 10.1016/j.phymed.2010.09.007

Xiang, H., Liu, Y., Zhang, B., Huang, J., Li, Y., Yang, B., et al. (2011). The antidepressant effects and mechanism of action of total saponins from the caudexes and leaves of Panax notoginseng in animal models of depression. Phytomedicine 18, 731-738. doi: 10.1016/j.phymed.2010.11.014

Yang, C.-Y., Wang, J., Zhao, Y., Shen, L., Jiang, X., Xie, Z.-G., et al. (2010). Antidiabetic effects of Panax notoginseng saponins and its major anti-hyperglycemic components. J. Ethnopharmacol. 130, 231-236. doi: 10.1016/j.jep.2010.04.039

Yang, H., Kim, J. Y., Kim, S. O., Yoo, Y. H., and Sung, S. H. (2014). Complete ${ }^{1} \mathrm{H}-\mathrm{NMR}$ and ${ }^{13} \mathrm{C}-\mathrm{NMR}$ spectral analysis of the pairs of $20(S)$ and $20(R)$ ginsenosides. J. Ginseng Res. 38, 194-202. doi: 10.1016/j.jgr.2014.05.002

Yang, Q., Wang, P., Cui, J., Wang, W., Chen, Y., and Zhang, T. (2016). Panax notoginseng saponins attenuate lung cancer growth in part through modulating the level of Met/miR-222 axis. J. Ethnopharmacol. 193, 255-265. doi: 10.1016/j. jep.2016.08.040

Yang, X., Xiong, X., Wang, H., and Wang, J. (2014). Protective effects of Panax notoginseng saponins on cardiovascular diseases: a comprehensive overview of experimental studies. Evid. Based Complement. Alternat. Med. 2014:204840. doi: 10.1155/2014/204840

Yang, W.-Z., Bo, T., Ji, S., Qiao, X., Guo, D.-A., and Ye, M. (2013). Rapid chemical profiling of saponins in the flower buds of Panax notoginseng by integrating MCI gel column chromatography and liquid chromatography/mass spectrometry analysis. Food Chem. 139, 762-769. doi: 10.1016/j.foodchem.2013. 01.051

Yuan, H. D., Quan, H. Y., Zhang, Y., Kim, S. H., and Chung, S. H. (2010). 20(S)Ginsenoside Rg3-induced apoptosis in HT-29 colon cancer cells is associated with AMPK signaling pathway. Mol. Med. Rep. 3, 825-831. doi: 10.3892/mmr. 2010.328

Zhang, C., Yu, H., and Hou, J. (2011). Effects of 20 (S) -ginsenoside Rh2 and 20 (R) ginsenoside Rh2 on proliferation and apoptosis of human lung adenocarcinoma A549 cells. Chin. J. Chin. Mater. Med. 36, 1670-1674.

Zhang, W., Bai, X., Wang, Y., Zhao, B., Zhao, Y., Hou, W., et al. (2014). SERS study of different configurations of pharmaceutical and natural product molecules ginsenoside $\operatorname{Rg} 3$ under the interaction with human serum albumin on simple self-assembled substrate. Spectrochim. Acta A Mol. Biomol. Spectrosc. 117, 210-215. doi: 10.1016/j.saa.2013.07.087

Zhou, N., Tang, Y., Keep, R. F., Ma, X., and Xiang, J. (2014). Antioxidative effects of Panax notoginseng saponins in brain cells. Phytomedicine 21, 1189-1195. doi: 10.1016/j.phymed.2014.05.004

Zhu, J., Fan, X., Cheng, Y., Agarwal, R., Moore, C. M. V., Chen, S. T., et al. (2014). Chemometric analysis for identification of botanical raw materials for pharmaceutical use: a case study using Panax notoginseng. PLoS One 9:e87462. doi: 10.1371/journal.pone.0087462

Conflict of Interest Statement: The authors declare that the research was conducted in the absence of any commercial or financial relationships that could be construed as a potential conflict of interest.

Copyright (c) 2018 Peng, Yi, Zhang, Ding and Le. This is an open-access article distributed under the terms of the Creative Commons Attribution License (CC BY). The use, distribution or reproduction in other forums is permitted, provided the original author(s) and the copyright owner are credited and that the original publication in this journal is cited, in accordance with accepted academic practice. No use, distribution or reproduction is permitted which does not comply with these terms. 